Advances in Parasitology (2015) vol 88, pp 123-164

\title{
Chronobiology of Trematode Cercarial Emergence: from Data Recovery to Epidemiological, Ecological and Evolutionary Implications
}

\author{
André Théron
}

CNRS, UMR 5244, Ecologie et Evolution des Interactions (2EI), Université de Perpignan Via Domitia, Université, Perpignan, France E-mail: theron@univ-perp.fr

\begin{abstract}
One major challenge for parasites with complex cycles consists to succeed in the transmission from one host to the next host. To maximize the probability of encountering the right host, numerous trematode species have selected various emergence rhythms occurring during the escape of the short-lived cercariae from the mollusc host. Cercarial shedding patterns are beautiful examples of adaptation of the parasite for a successful rendezvous with its subsequent host. In this review, after an analysis of the technical and statistical aspects specific to such studies, we compile the knowledge and unresolved issues we have about the synchronization of these rhythms, their genetic support and the role of the host physiology or activity. We are also interested on how cercarial rhythmicity influences cercarial densities in waters of transmission sites and then the risk of host infection in case of schistosomiasis. Ecological significance of the inter- and intra-specific diversity of these rhythms is emphasized as well as the evolutionary implication of new chronotypes resulting from the capture of new host species and promoting reproductive isolation and alloxenic speciation. Currently, genome sequence data now available for some trematodes such as the schistosomes provide an unprecedented resource for new research approaches that should contribute identification of the genes and mechanisms involved in determining the cercarial shedding rhythms observed.
\end{abstract}

\section{1- Introduction}

Forty years ago, Hawking (1975), in his article on "Circadian and other Rhythms of Parasites" published in Advances in Parasitology, was probably one of the first to give an overview of the importance of chronobiological phenomenon in parasitology. Numerous examples showed the diversity of parasite organisms concerned (coccidia, flagellates, helminths): the diversity of biological levels involved, cellular (i.e. rhythmicity of cell divisions in Plasmodium), individual (i.e. periodic migration of the intestinal tape worm Hymenolepis diminuta), populational (i.e. synchronous emergence of trematode cercariae); the diversity and complexity of the mechanisms involved and the possible biological purpose of all these rhythms particularly in the transmission dynamics of parasites.

Here we propose to focus on the emergence periodicity of the cercariae of trematodes shed by their intermediate mollusc hosts, a phenomenon which was first recorded by Tanabe (1923) affecting the great majority of Digenean species as reviewed by Yamaguti (1970). With the Giovannola's experiments (1936), abiotic factors influencing the periodic emergence of cercariae, mainly light and temperature variations, were studied and rapidly the question raised of the possible role of the mollusc host physiology or activity on this cercarial rhythmic process. With the increasing interest for cercarial chronobiology, several technical approaches were developed to facilitate the data recovery and cercariae counts while statistical methods adapted to cyclic events were used for data analyses. By the development of various field apparatus allowing the direct recovery of cercariae in natural 
waters and the measurement of daily variations of their densities, cercariometry was incorporated within epidemiological studies for cercariae of medical importance as in case of schistosomiasis or swimmer's itch. The demonstration of the genetic basis of the rhythms was of great importance to support the widely accepted hypothesis that cercarial rhythms were selected adaptations increasing meeting probabilities between the free living and shortlived larval stages of the parasite and the host they have to infect. In the context of population biology studies, intra-specific diversity of cercarial chronobiology was used as behavioural markers to estimate genetic variations between populations of parasites exploiting different host resources or heterogeneous environments. More recently, divergences in time shedding of cercariae were considered, through its implications on host specificity and habitat choice as a possible mechanism which can promote host lateral transfer, then reproductive isolation and sympatric speciation.

\section{2- Techniques, Materials, Methods and Statistics}

As numerous bioperiodic phenomena, rhythmic emergence of cercariae is widely sensitive to environmental conditions. For this reason, experimental analysis of these rhythms needs the environmental factors and techniques used to be strictly defined and standardized in order to obtain significantly representative and comparative results.

\subsection{Environmental conditions}

Two abiotics factors, photoperiod and thermoperiod, are of major importance and then have to be controlled imperatively. Concerning photoperiod (i.e. alternation of light and dark cycles on a 24-h time lap), two possibilities exist: the use of the natural or an artificial light/dark (LD) regimen. Artificial photoperiod has several advantages compared with the natural one, particularly for the control and the possibility of variation of the light (LL) and dark (DD) period ratio as well as light intensity and quality. Artificial photoperiod allows also to maintain identical illumination conditions, whatever the period of the year at which the study is carried out, and then to have similar references for valuable comparison of results from different experiments. Light intensity and quality seems to have little effect on the shedding pattern of the majority of the cercariae (Asch, 1972); however, a rough transition between light and dark is susceptible to provoke artefacts (cercarial shedding spurs) more or less pronounced. The use of electronics or mechanical apparatus allowing simulation of dawn and dusk avoids this trouble. Concerning temperature, this factor seems less important than light (Valle et al., 1973) and in most of the studies (except specific study of this parameter-see Section 3.2) experiments are carried out at constant temperature selected around that of the natural habitat of the snail hosts. In addition we have to note that whatever the environmental conditions selected a period of acclimatization of the infected molluscs (2e3 days) is recommended before collection of data as well as an appropriate supply of food during the experiment.

\subsection{Fractioning the cercarial emergence}

Formal description of the shedding patterns of cercariae needs careful timedependent collection methods to recover the cercariae produced by the mollusc over the monitored period at regular time intervals during a minimum of $24 \mathrm{~h}$. Depending on the authors, time intervals between two samples range between 1 and $12 \mathrm{~h}$. The choice of this time fraction depends on the goal fixed by the study. For a detailed analysis of chronobiological profiles, a 1-h interval is generally used, to study the influence of some factors (i.e. photoperiod inversion, etc.) the interval can be increased to 6 or $12 \mathrm{~h}$.

The periodic collection of the cercariae can be done manually or automatically. Manually, molluscs are regularly removed from their beakers to another one with water at 
the same temperature or alternatively molluscs remain in the beakers and the water is changed. This method presents the great disadvantage of a quasi-continuous presence of the experimenter during all the duration of the study which from the one hand, limits the possibility of multiple or long consecutive experiments and on the other hand, needs manipulations during the dark period susceptible to interfere with the chronobiological phenomenon. Automatic sampling of the cercariae is more adapted but requires specific apparatus which are not available on the market. Four original apparatus, based on two different concepts have been proposed.

- Automatic sampling of cercariae by snail transfer: (1) Disko (1978), (2) Williams et al. (1984). Every one (1) or two (2) hours, infected snails are automatically transferred into a different line of beakers (1) or into a different line of a compartmentalized plastic tray (2). Snails were suspended on a crossbeam, individually free (1) or placed into glass beaker of $10 \mathrm{~mL}$ (2). For the Disko's apparatus it is the cross-beam which moves and for the Williams's apparatus it is the plastic tray.

- Automatic sampling of cercariae by water drain and filling of snail aquaria (Figure 1): (1) Mcllraith (1979), (2) Théron (1982). The two apparatus collect at $15 \mathrm{mn}$ (1) or hourly (2) intervals the water where infected molluscs are maintained, using a siphoning action (1) or flood gates (2). The water samples with cercariae are stocked in glasses of an automatic collector fraction.

Whatever the apparatus concerned, two difficulties may be encountered, (1) when cercariae show an "adhesive" behaviour and then are retained on the aquaria walls (i.e. Schistosoma japonicum cercariae), (2) when cercariae rapidly encyst within the infected snails (i.e. Echinostoma cercariae).

\subsection{Counting the cercariae}

In the absence of an automatic method to count cercariae, the larvae are enumerated manually with visual tally counts. We have tested various apparatus using densitometric, optic or volumetric detection without success mainly because time necessary for water sample preparation was higher than that of the manual count. The little size of the larvae, the easily breaking of the tail or the presence of particles in the water (snail feces or vegetal fragments) renders the use of such apparatus particularly difficult.

Counting can be carried out either from one or several aliquots (generally of $1 \mathrm{~mL}$ ) of the collected water sample or exhaustively from the total sample. In the first case, cercariae are killed with formalin, the aliquots placed on a Petri dish with a counting grid. In case of total counts, the water samples containing the cercariae are filtered through a polyamide filter of 20-mm pore size (Théron, 1979), or a fibre glass disc (Rowan, 1957), stained with Lugol's iodine solution and counted under a stereoscopic microscope. 


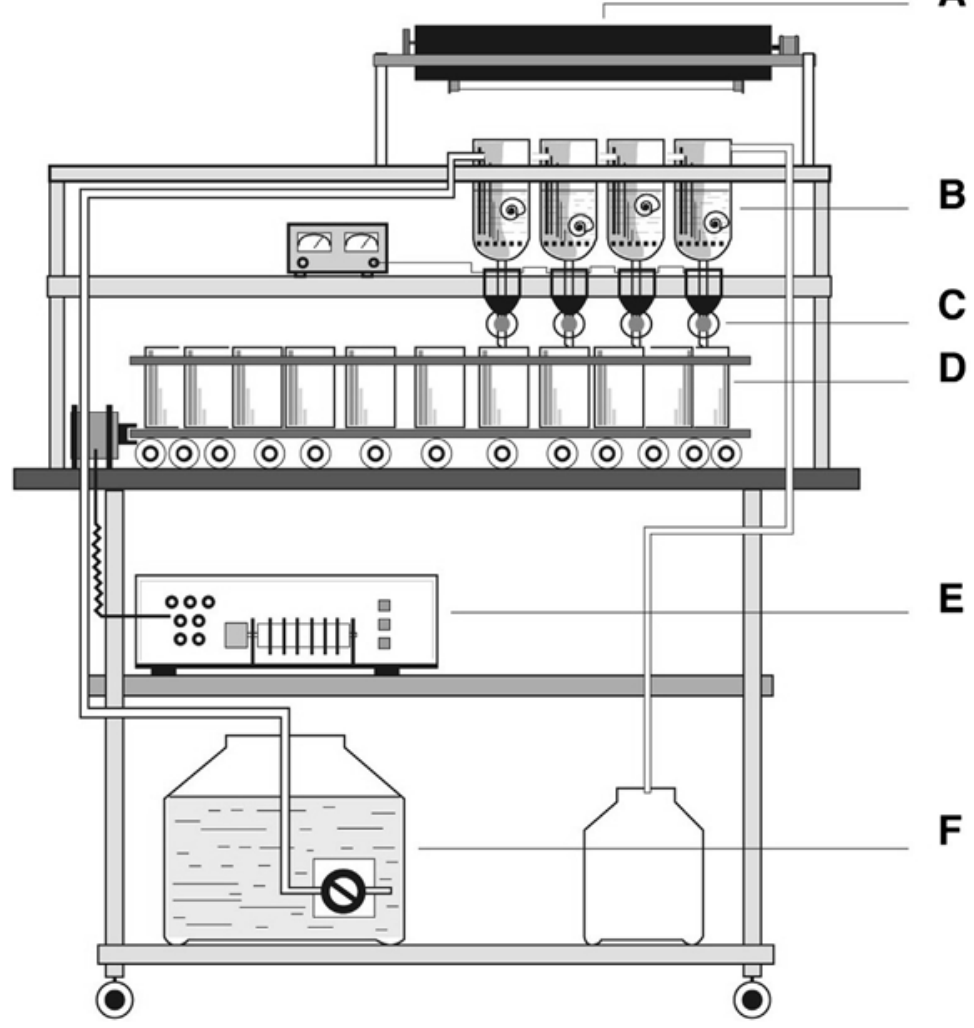

Figure 1 Specific apparatus for automatic hourly sampling of cercariae by water drain (A: dawn and dusk illuminator, B: aquaria with infected snails, C: flood gates, D: revolving collector, E: control unit, F: water supply. Modified from Théron (1982).

\subsection{Data and statistical analysis}

Data collected on the number of cercariae shed at regular intervals of time are graphically represented as histograms which allow the characterization of shedding patterns by the time at which peak emergence is reached, the beginning and the end of the shedding period. This linear approach of the data analysis was not appropriated for statistical comparison. Chassé and Théron (1988) have proposed the use of the circular statistics (Batschelet, 1981) to test the significance of variation between individual and population rhythms of cercarial emergence for which we recall briefly the basic principles. Circular statistics deal with the analysis of points distributed over a circle. For cercarial emergence, the initial histogram (Figure 2 ) is translated on a circle $(3601 / 424 \mathrm{~h}$ ) on which hourly data are represented by unit vectors (Figure 2) each characterized by an angle and their length.

It is then possible to calculate for each daily emission the resultant and the mean vector (Figure 2), its corresponding mean angle (representing the mean shedding time of the cercariae) and its length (representing the 
(a))
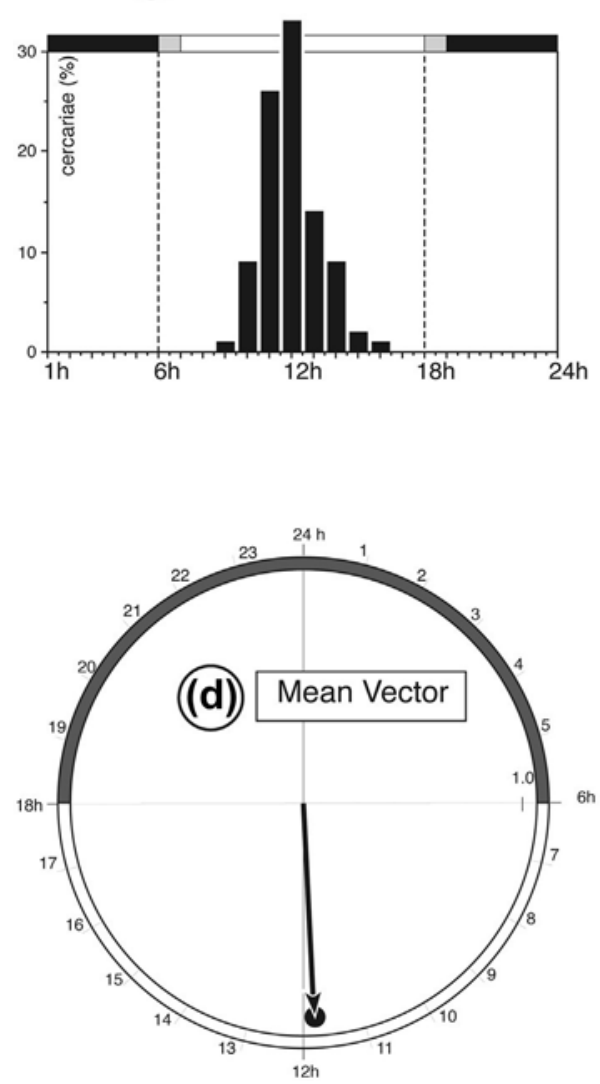

Circular data

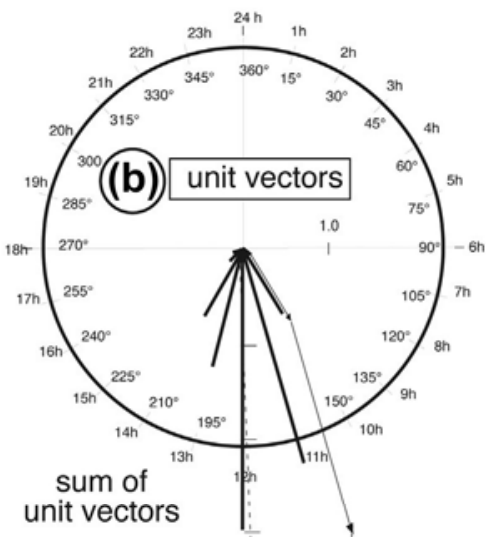

(c))

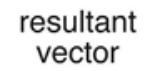

Figure 2 Basic principle of the transformation of linear (a: histogram of the hourly cercarial production) to circular data (b: unit vectors on a circle) and graphic calculation of the resultant (c) and the mean vector (d). The daily shedding pattern of the cercariae produced by a snail is now plotted by one point characterized by its mean angle and the length from the centre of the circle. This transformation allows the use of various statistical tests (see text).

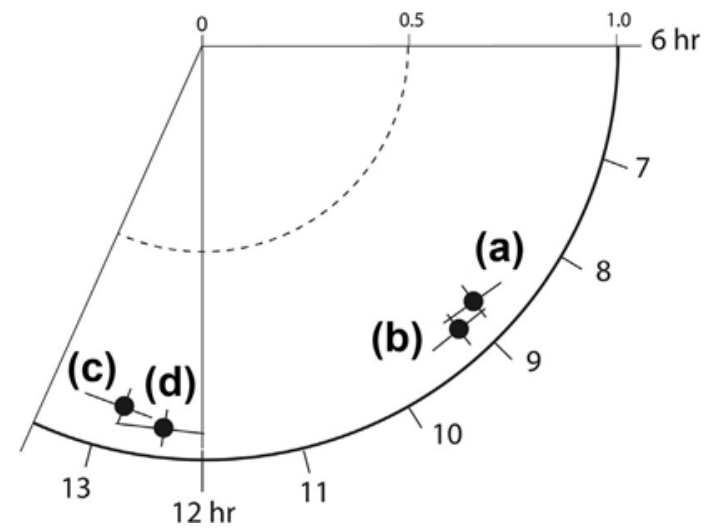

Figure 3 Overall average of the mean vectors and their confidence ellipses for four species of Schistosoma from Niger: (a) S. curassoni, (b) S. bovis, (c) S. haematobium, and (d) S. mansoni. Modified from Mouchet et al. (1992). 
dispersion of the data). When several daily rhythms for cercariae from the same individual snail or for several snails of the same population are analyzed, it is possible to calculate the average of the mean vectors, its angular variance and its confidence ellipse (Figure 3). Two or more samples can be compared statistically to test homogeneity and significant differences by the MardiaWatson-Wheeler test (Mardia, 1972). Bogéa et al. (1996) have used periodogram, single and population cosinor analysis (Van Cauter and Huyberects, 1973) to estimate the period and calculate the acrophases of the rhythms. Homogeneity of groups and significant differences between acrophases were detected using the Bingham test (Bingham et al., 1982).

\section{3-Synchronization of the rythms}

\subsection{Endogenous or exogenous rhythms?}

When being interested by a bioperiodic phenomenon, one of the first questions raised is whether the endogenous or exogenous origin of the rhythms studied? Persistence of the rhythm in constant environmental conditions is generally considered as a strong argument in favour of an endogenous origin of the rhythm (Aschoff, 1960).

Experiments carried out on cercarial emergence rhythms in the absence of photoperiod and thermoperiod (or "free running" experiments) demonstrated that rhythmicity of the emergence disappears under continuous light as well as continuous obscurity. These experiments, carried out principally by Valle et al. (1973) and later reproduced by several authors with various hosteparasite combinations, seem to justify the exogenous character of the cercarial emergence rhythms.

One important remark has to be done relatively to this matter. Biological rhythms can be expressed at different, molecular, cellular, individual or populational levels through a regular repetitive activity of the concerned biological structure. Important to note is that, if in cercarial shedding rhythms, cercarial stage alone is implicated in the process, the observed rhythmic phenomenon is not an activity regularly repeated in one or by one individual, but the sum of several unique events carried out, at the same time and only once during their life span, by several individuals (cercariae). In this case, cercarial rhythmicity is only expressed at a populational level and the question of the endogenous basis of these cercarial rhythms falls. The situation will be different if sporocysts (or rediae) in which cercariae develop were implicated in the phenomenon (see Section 3.3). In this case, it will be a true individual rhythm since the same larvae (sporocysts or rediae) repeats periodically the same activity during several consecutive days (e.g. opening/closing the birth pore by where the cercariae could escape).

\subsection{Which synchronizer?}

Whatever they have an exogenous or endogenous basis, bioperiodic phenomena are strongly influenced by environmental factors and we call synchronizer, entraining agent or "zeitgeber", any factors which periodic variations aresusceptibletomodifytheperiodand/orthephaseofabiological rhythm (see Halberg et al., 1977 for definition of terms used in chronobiology). Several external factors exhibiting daily variations (i.e. photoperiod, thermoperiod, salinity, $\mathrm{pH}$, water level, etc.) can act as synchronizer of these rhythms, however, not the same value or power and a hierarchical scale between them can be established. Concerning cercariae of schistosomes and, probably other trematodes, numerous experiments have well established that photoperiod may be considered as the preponderant synchronizer even if thermoperiod, in the absence of photoperiod, is able to synchronize cercarial emergence (Valle et al., 1973; Nojima et al., 1981). 
Various experiments have been performed to demonstrate the respective role of photoperiod and thermoperiod and consequences of their variations on the chronobiological patterns. Since 1936, Giovannola then Kuntz (1947), Luttermoser (1955), Valle et al. (1973), Asch (1972), Glaudel and Etges (1973) and Théron (1975) have shown that an inversion of the photoperiod rapidly provokes an inversion of the cercarial emergence rhythm.

When snails were maintained in constant conditions of light or dark and in absence of thermoperiod, the cercarial emergence was not inhibited but the circadian rhythm disappears (Williams et al., 1984). In contrast, in the absence of photoperiod but with the establishment of a thermoperiod, the circadian shedding rhythm was maintained (Valle et al., 1973). Nojima et al. (1981) have estimated at $3 \mathrm{C}$ for Schistosoma mansoni, the sufficient oscillation for maintaining by thermoperiod, the emergence rhythm in continuous light. Asch (1972) demonstrated that about $100 \mathrm{e} 200 \mathrm{erg} / \mathrm{cm}^{2} / \mathrm{s}$ was the minimum amount of incident energy required to induce cercarial release and that different quality of light, upper and lower ends of the spectrum as well as the full spectrum of visible light, were able to elicit cercarial emergence.

Comparison of the changes in emergence patterns at the end of a continuous LL or DD period has shown that inhibition of emergence is sometimes more important than stimulation in determining daily emergence patterns. Then, for some species of trematodes (i.e. Ribeiroia marini or Proterometra macrostomum), cercarial emergence rhythmicity resulted more from an inhibitory effect by light or darkness than from a stimulating effect (Théron, 1975; Lewis et al., 1989).

Nojima and Sato $(1978,1982)$ then Raymond and Probert (1987) showed that the interjection of a period of darkness ranging from $5 \mathrm{~s}$ to $1 \mathrm{~h}$ during the photophase stimulated immediately the cercarial emission of Schistosoma haematobium inducing a second peak of emergence. The rapidity of the response of the cercariae to the change of light intensity seems to indicate the presence of a pool of cercariae, out of the sporocysts, waiting for emergence and highly sensitive to the external conditions through the shell of the snail host. This phenomenon, known as "shadow response" was not observed in case of S. mansoni.

\subsection{How the synchronizer acts?}

The possible participation of the mollusc host (Figure 4(a)) on the rhythmic release of cercariae will be discussed later (see Section 4.1). However, independent of this aspect, the question raises of which intra-molluscan stage of the parasite receives (directly or indirectly) the information gave by the synchronizer? Three theoretically possible hypotheses can be advanced

(Figure 4(b)):

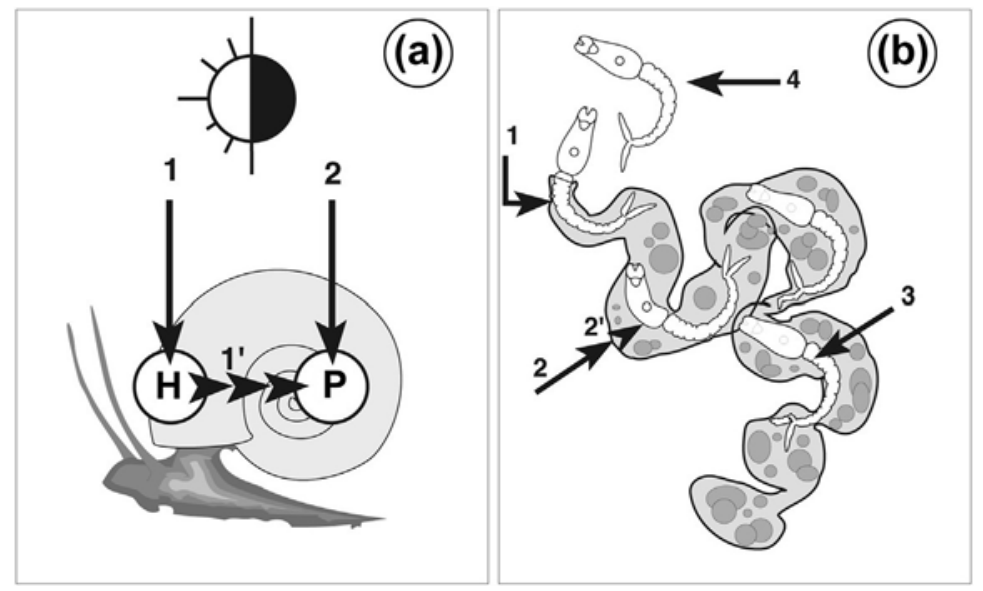


Figure 4 Different hypotheses of the way by which the external factors could be perceived by the parasite. (a) the synchronizer (photoperiod) can act indirectly $(1,10)$ on the parasite (P) via the host $(\mathrm{H})$ or directly $(2)$ on the parasite $(\mathrm{P})$. (b) the external signal can be received by the sporocyst alone (1); the sporocyst then the cercariae $(2,20)$; the cercariae alone inside (3) or outside the sporocyst (4).

1. cercariae are alone implicated in the rhythmic phenomenon;

2. daughter sprorocysts (or rediae) are alone implicated in the rhythmic phenomenon of cercarial release;

3. daughter sprorocysts (or rediae) and the cercariae are both involved, separately or consecutively, with two possibilities of transmission of the information: from the cercariae to the sporocyst or inversely from sporocyst to the cercariae.

At present, we have few arguments in favour of one or the other of these processes. Personal observations of the cercariae of Ribeiroia (genus in full) marini, a parasite of Biomphalaria glabrata, showed that several hours before leaving the snails (strictly at night) cercariae accumulated during the light period outside of the rediae within the hemolymph of the snail hepatopancreas. An argument for a direct (or indirect) action of the synchronizer on the cercariae but probably anticipated by another signal on the rediae.

Results of the experiments carried out by Théron and Combes (1983) on the genetic aspects of cercarial rhythms of S. mansoni gave interesting information on this matter. Intraspecific crosses between two strains of this parasite species (see Section 5.1), one with an early emergence pattern (SmGUA, peak at 11 a.m.) the other with a late emergence (SmBRE, peak at 4 p.m.) lead to parasites at the first generation, whose cercarial emergence pattern showed two consecutive peaks of emission each corresponding to the parental phenotypes used (see Figure 6). Taking into account that snail infections were monomiracidial, then the cercariae produced by asexual multiplication and are broadly genetically identical, it was difficult to understand how genetically identical cercariae respond for one part with an early shedding and for the other part with a late shedding? The existence of this double peak can be understood only if we consider that the daughter sporocysts participate to the chronobiological process of cercarial emergence. In these conditions, one can envisage that daughter sporocysts of S. mansoni, heterozygous for the alleles responsible of the early or late phenotype, are able to liberate some of their cercariae when they receive the first signal, then inhibit the cercarial output and again allow the release of the remaining cercariae when they receive the second signal. This hypothesis needs almost one condition: the existence of an anatomical structure capable to permit or to block the exit of the cercariae within the daughter sporocyst. Direct observations through the translucent shell of living infected albino snails in period of cercarial shedding and histological and ultrastructural studies of the sporocyst of S. mansoni but also Schistosoma rodhaini (schistosomes of the lateral spined egg group) demonstrate the presence of a well-structured birth pore (Figure 5) at one of the extremity of the sporocyst (Théron and Fournier, 1982; Fournier and Théron, 1985; Théron and Touassem, 1989). Ultrastructural and histochemical observations of this terminal portion of the 


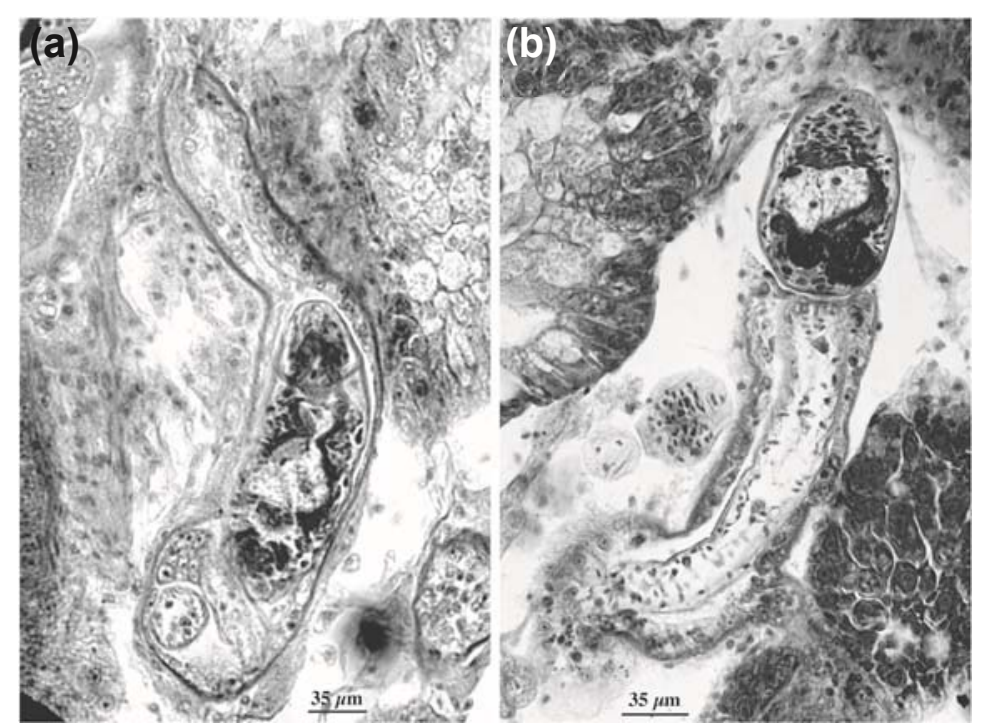

Figure 5 Histological sections at the terminal portion of the daughter sprorocyst of Schistosoma mansoni within the interlobular spaces of the hepatopancreas of Biomphalaria glabrata showing: (a) a cercaria migrating towards the birth pore; (b) a cercaria escaping the sporocyst through the birth pore.

sporocysts showed the presence of acetylcholinesterase activity and of nervous and muscular structures allowing the active opening and closure of the birth pore with the possibility of controlling the exit of the cercariae. The interesting fact is that identical analyses carried out on three other species of schistosomes but belonging to the terminal spined egg group (Schistosoma haematobium, Schistosoma bovis and Schistosoma intercalatum) demonstrate that birth pore was absent for these species and that cercariae leave the sporocyst by burglary, rupturing the body wall (Théron, pers. observ.). For these species one can envisage that cercariae are alone implicated at the signal reception and not the sporocysts. These results illustrate that among the same genus of parasites, mechanisms involved in cercarial release from the sporocyst could be different as it would be between trematodes with sporocysts and those with rediae for which a well-differentiated birth pore exists.

\section{4- Host-parasite and parasite-parasite interactions}

\subsection{The host mediation?}

As for various aspects of hosteparasite relationships, the obligate question of the respective role of the host and the parasite on the cercarial rhythmic emergence phenomenon remains open. On others words, is the snail intermediate host implicated as mediator between the external environmental synchronizer and the intra-molluscan larval stages of the parasite?

Literature gives conflicting interpretations. For Asch (1972), working on the S. mansoni/B. glabrata combination, "the response to the synchronizer is probably not due to a direct interaction between that external influence and the mature cercariae buried within the tissues of the snail. It is highly probable that the cercariae are responding to a rhythm(s) of the snail, which is controlled to some extent by illumination". Asch's arguments were mainly based on the idea that light cannot pierce either the shell or the tissues of black pigmented snails. This hypothesis was shared by Valle et al. (1973) but without giving new experimental complements. We don't agree with the assumption of Asch, since light penetrates through the shell as attested by the possibility of observing through the shell some 
internal organs of the snail or many times, daughter sporocysts or rediae for detection of infection even for black pigmented snails. Moreover, results of Asch (1972) demonstrated that a very low luminous energy level was sufficient for the induction of cercarial release. Anderson et al. (1976) were also of the opinion of host participation. Taking into account a positive correlation between periods of locomotor activity of Lymnaea stagnalis and the diurnal periods of emergence of the cercariae of Trichobilharzia ocellata, they concluded that: "The snail activity causes the release of cercariae. It is possible that snail activity facilitates the migration of mature cercariae to point of exit." However, correlation is not a demonstration. Mitchell et al. (1983) conclude also for Gorgoderina vitelliloba cercariae that "natural rhythms of cercarial emergence are controlled by stimuli originating in both the host and the outside environment but not in the sporocyst." These authors have compared cercarial emergence from intact molluscan bivalve hosts (Pisidium spp.) with cercarial shedding patterns obtained from sporocysts on isolated gill lamellae maintained in vitro. In the absence of environmental stimuli (constant light and $\mathrm{T}$ ), cercarial emergence was rhythmic from intact molluscs, but arrhythmic from gill lamellae with sporocysts. However, under influence of diurnal temperature fluctuations, emergence of cercariae from sporocysts and gills in vitro became rhythmic. We must note that the host/ parasite combination used in these experiments involves Lamellibranch mollusc hosts which have the opportunity to close their valves and then to interfere physically with the cercarial shedding process. This model (as well as those with prosobranch snails with an operculum) differs widely from that with a pulmonate snail as intermediate host, for which the "snail gate" is always opened for the exit of the cercariae.

The alternative of an absence of host mediation on the cercarial chronobiological phenomenon has been documented by Williams and Gilbertson (1983a) with the S. mansoni/B. glabrata combination, The factor controlling the rhythm of S. mansoni cercarial emergence may be independent of the snail . we have not found any rhythms of the snail that correlates with the rhythm of cercarial emergence". By perturbing the locomotor activity and the heart pulsation rate by absence of feeding during some days (Williams et al., 1984) and Williams and Gilbertson (1983b) showed that cercarial emergence rhythms were not modified compared with control infected snails. On the other hand, they demonstrated that under normal photoperiod, snails showed inter-individual differences in their locomotor and cardiac activities while cercarial shedding patterns remained identical. They conclude that light may act directly on the schistosome to elicit emergence from the snail.

Taking the opportunity of a relative large specificity of some species of Schistosoma towards their intermediate snail hosts, a series of experiments was carried out with the goal to detect significant variations of the cercarial shedding pattern when the same strain of parasite develops within different snail hosts. The hypothesis was, if the host participates as mediator, different strains, species or genus of snails do not transmit with and identical manner the information gave by the external synchronizer and then can induce variations at the level of the cercarial emergence patterns. When S. mansoni cercariae were produced by two strains of B. glabrata, one albino, the other black pigmented, the shedding pattern was not significantly different (Théron, 1980a). No more difference was observed between S. rodhaini cercariae shed from two different species of snail hosts, B. glabrata versus B. pfeifferi (Théron, 1989). For S. mansoni infecting two different African species of Biomphalaria (B. sudanica and B. stanleyi) peak cercarial production in both species was between 12.00 and $14.00 \mathrm{~h}$ but there was a significant interaction between the snail species and the time of the day when cercariae were shed. B. sudanica shed proportionately more cercariae than B. stanleyi early in the day and proportionately less towards the end of the day (Kazibwe et al., 2010).

Even from snails belonging of two different genera, Bulinus truncatus versus Planorbarius metidjensis, cercarial emergence pattern of S. bovis was not affected (Mouahid and Théron, 1986). Results of these three experiments give strong arguments for the absence of mediation of the host (almost for these parasite species) as well as those of the following 
experiment. For the R. marini/B. glabrata combination, it has been demonstrated that light acts directly on the intra-molluscan parasite stages through the shell of its pigmented snail host. Cercarial shedding pattern of R. marini is strictly nocturnal. It is not dark that stimulates cercarial shedding, but light that inhibits the cercarial emergence (Théron, 1975). When during the illuminated period, the shell of the snails was made opaque by covering it with an aluminium paper but allowing the snail to remain free and active with the head-foot and tentacles outside of the shell, R. marini cercariae were shed in the first hour following the shell covering. This experiment demonstrates almost for this hosteparasite combination that the snail does not act as mediator in the shedding process of the parasite larvae.

\subsection{Parasiteeparasite interactions}

Beside the hosteparasite relationships, one can consider the possibility of an interaction between the numerous larval stages (daughter sporocysts or rediae) closely associated within the interlobular space of the digestive gland and/or at the ovotestis level. Several experiments have been carried out using snails simultaneously infected with two different strains, species or genus of parasites, each having a distinct pattern of cercarial emergence. Whether the trematodes belong to different genera (i.e. R. marini and S. mansoni, Théron and Moné, 1986; Echinoparyphium recurvatum and Plagiorchis sp., McCarthy, 1999), to different species of a same genus (i.e. S. haematobium and S. bovis (Mouahid et al., 1991); S. mansoni and S. rodhaini (Norton et al., 2008; Standley and Stothard, 2012)) or to different strains of a same species (i.e. early and late S. mansoni, Théron et al., 1997), their coexistence within the same intermediate host does not influence the emergence rhythms of each type of cercariae. The emergence of the earliest cercariae does not trigger off the emission of the latest one. These results suggest that there is no communication (e.g. by way of a pheromone) between the sporocysts even from strains of the same species, or if there is a communication between intra-strain sporocysts, that the receptors involved differ from one chronobiological strain to the other. This absence of interference can be also viewed as another argument against the host's direct intervention in chronobiological phenomena of cercarial emergence. Additionally, comparison between mono- and plurimiracidial snail infections showed no significant difference between the peak position related to the number of cercariae produced daily (Bogéa et al., 1990).

\section{5- Genetic support}

Among digeneans, schistosomes constitute an interesting model to approach the genetic basis of cercarial chronobiology. They are gonochoric worms offering the possibility of experimental crosses by infection of mice with cercariae of identified sex. The use of the techniques of schistosome cloning by microchirurgical transplantation of sporocysts from a donor monomiracidial infected snail to a recipient snail allows to maintain separately male and female lineages of the parasite (Jourdane and Théron, 1980) facilitating mice infection with dual sex. On the other hand, schistosomes constitute a complex of various species which incomplete genetic isolation allows, almost within the same group, inter-specific crossbreedings (Taylor, 1970). These biological particularities and the chronobiological diversity among schistosome species (see Section 7.1) have been used to demonstrate that cercarial emergence rhythms are genetically controlled (Théron and Combes, 1983, 1988) and that inheritance of the chronobiological characters varies as the function of the strain or the species of parasite considered.

\subsection{Intra-specific cross-breedings between strains}

5.1.1 Homopatric strains (Théron and Combes, 1988)

Experimental crossing between early (peak emergence at $11.00 \mathrm{~h}$ ) and late (peak emergence at $16.00 \mathrm{~h}$ ) strains of S. mansoni ( $\mathrm{Sm} \mathrm{GUA(E)} \mathrm{x} \mathrm{Sm} \mathrm{GUA(L)),} \mathrm{originating} \mathrm{from} \mathrm{the} \mathrm{same}$ 
geographical place (Guadeloupe, French West Indies) produces individuals at the F1 generation, whose emergence patterns of cercariae are characterized by a single peak (13.00 h) intermediate between those of the parental schistosomes (Figure 6). No difference was observed between the schistosomes resulting from reciprocal male/female crossings. At the next generation (F2), chronobiological phenotypes of the individuals ranged from early to late parental patterns. Calculation of the respective ratios for each phenotype obtained is not possible in the case of schistosome worms (it is extremely difficult to isolate the lineage of a pair of worms), but such genetically controlled timing differences seem based on simple Mendelian inheritance as experiments reported above tend to suggest.

5.1.2 Heteropatric strains (Théron and Combes, 1983)

Intra-specific crosses between an early strain of S. mansoni from Guadeloupe and a late strain from Brazil, (Sm GUA(E) x Sm BRE(L)) produce schistosomes at the F1 generation, whose chronobiological phenotypes of cercariae (Figure 6) are characterized by two emergence peaks of similar intensity, one early at $07.00 \mathrm{~h}$ the other later at $13.00 \mathrm{~h}$.

\subsection{Inter-specific cross-breedings}

\subsubsection{Hybridization between S. mansoni and S. rodhaini (Théron, 1989)}

Hybridization between S. mansoni $(\mathrm{Sm})$ and $\mathrm{S}$. rodhaini $(\mathrm{Sr})$ both having a cercarial shedding pattern with a single emergence peak, diurnal for S. mansoni for the early ( $\mathrm{Sm}(\mathrm{E})$ ) and the late $(\mathrm{Sm}(\mathrm{L}))$ strains and nocturnal for S. rodhaini $(\mathrm{Sr}(\mathrm{N}))$, leads to first and second generation, schistosomes whose chronobiological phenotypes show two very unequal emergence peaks, one diurnal and the other nocturnal (Figure 7). However, depending on the early or late chronobiological strain of S. mansoni used in the cross-breeding, it was either the diurnal peak $(\mathrm{Sm}(\mathrm{E}) \times \mathrm{Sr}(\mathrm{N}))$ or the 

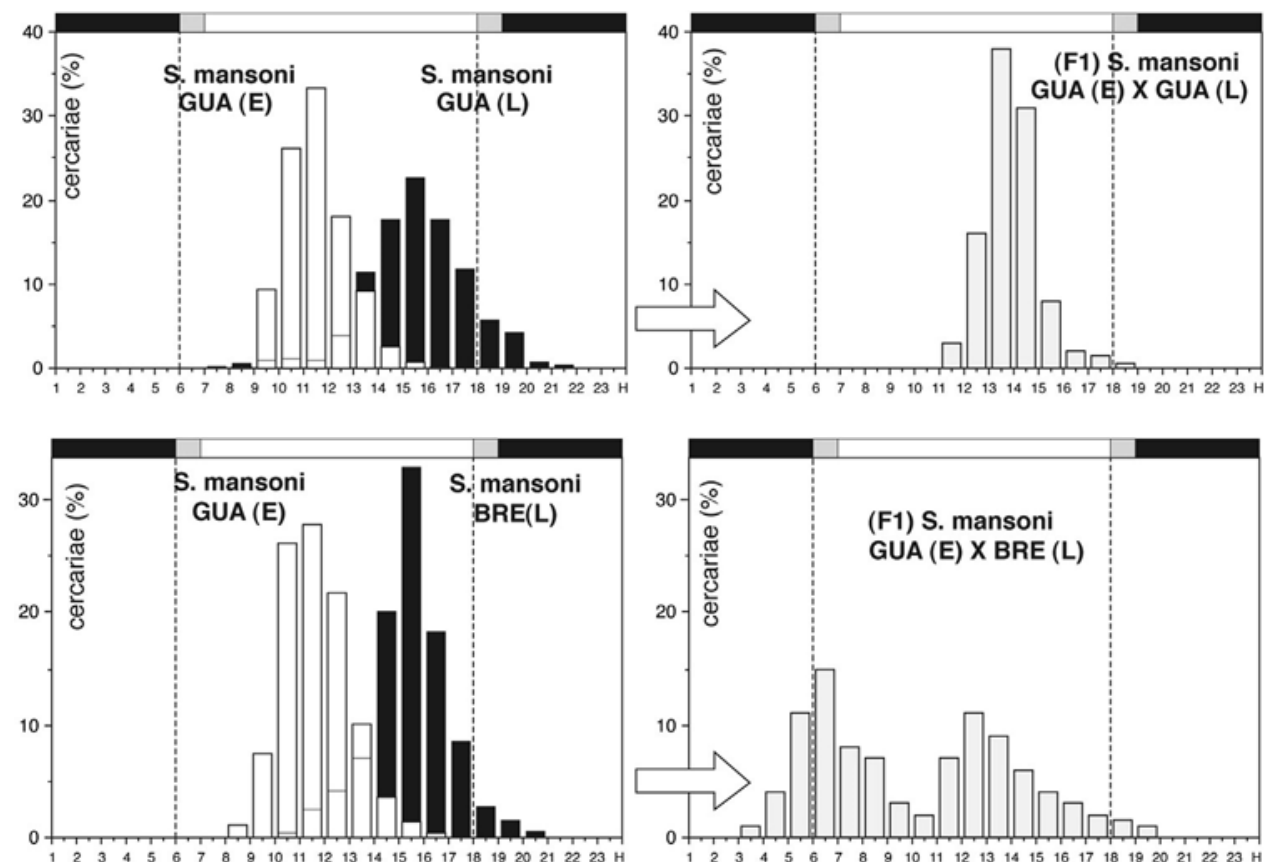

Figure 6 Cercarial shedding patterns of S. mansoni: (F1) hybrids resulting from a cross between two homopatric strains from Guadeloupe (GUA) and between two heteropatric strains from Guadeloupe (GUA) and from Brazil (BRE) each with an early (E) and a late (L) chronobiological phenotype. Note the different patterns obtained at the F1 generation. Modified from Théron (1986b). 


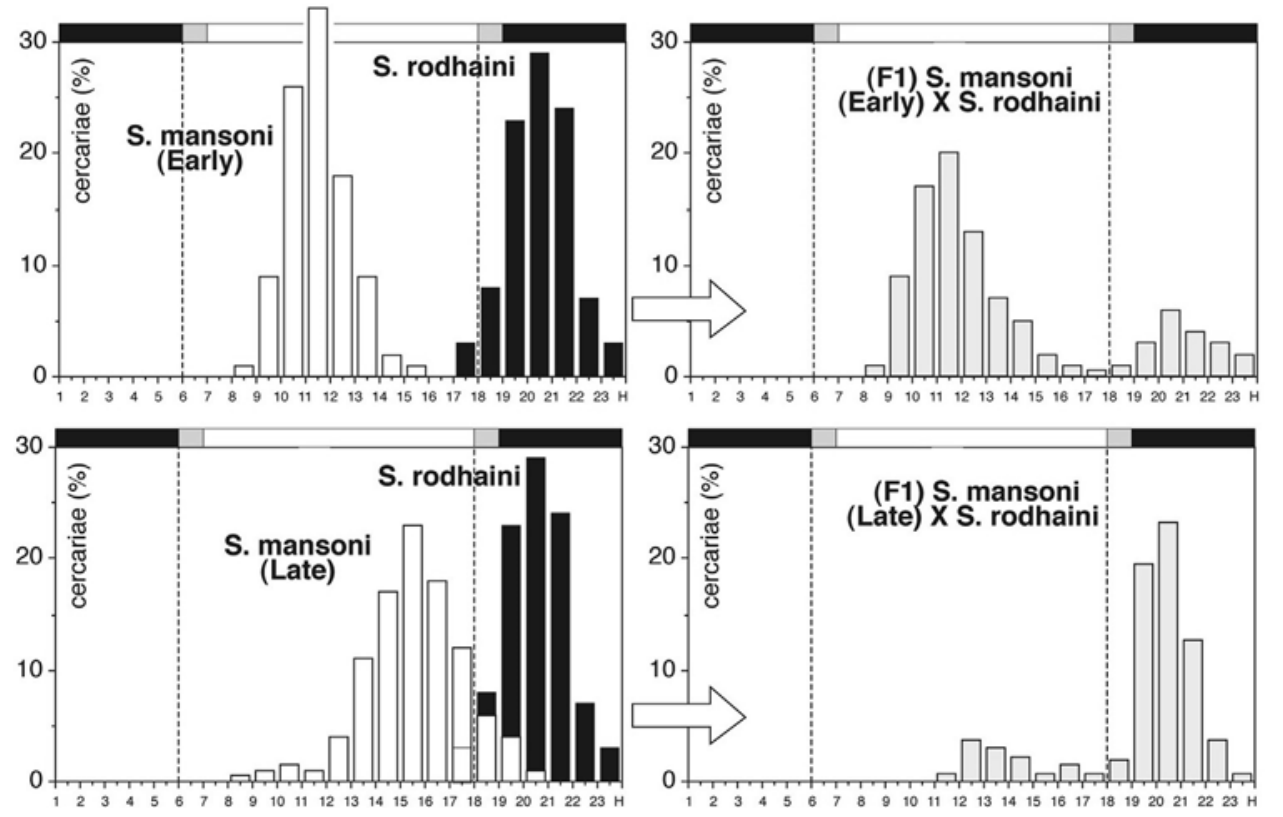

Figure 7 Cercarial shedding patterns of F1 hybrids resulting from a cross between Schistosoma mansoni and Schistosoma rodhaini. Note the different patterns obtained with the early and the late strain of S. mansoni. Modified from Therron (1989). 
nocturnal peak $(\mathrm{Sm}(\mathrm{L}) \mathrm{x} \mathrm{Sr}(\mathrm{N}))$ that was quantitatively preponderant (Figure 7).

5.2.2 Hybridization between S. haematobium and S. bovis (Pages and Théron, 1990a) The hybrid schistosomes obtained by this cross-breeding are characterized by a peak emergence between 08.00 and $09.00 \mathrm{~h}$ which is at the same position time that the earliest parent, $\mathrm{S}$. bovis, and $5 \mathrm{~h}$ earlier than the other parent, S. haematobium (Figure 8).
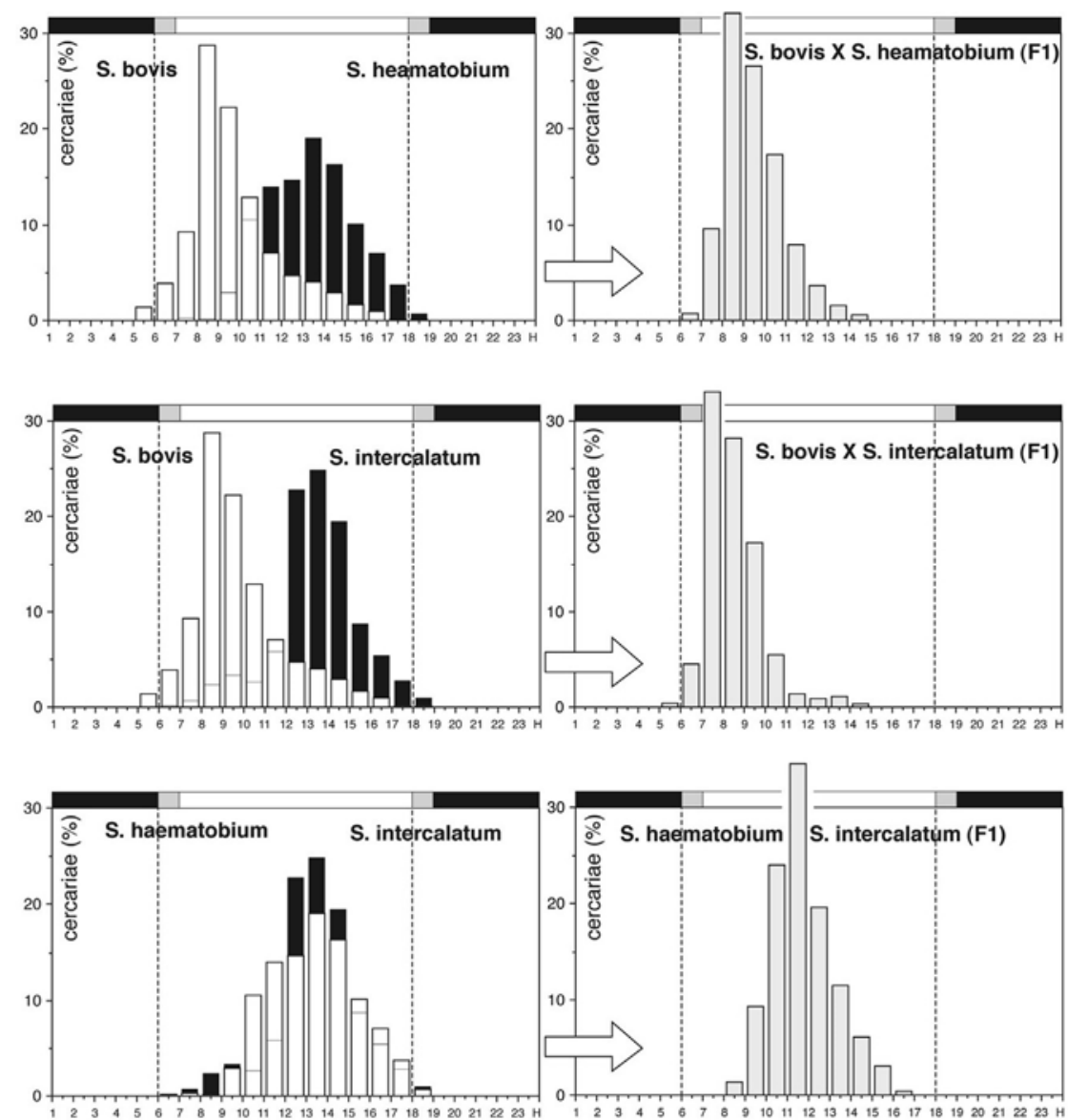

Figure 8 Cercarial shedding patterns of F1 hybrids resulting from crosses between Schistosoma bovis, Schistosoma haematobium and Schistosoma intercalatum. Modified from Pages and Théron (1990a).

5.2.3 Hybridization between S. bovis and S. intercalatum (Pages and Théron, 1990a,b)

The hybrid schistosomes show a very early peak emergence between 07.00 and $08.00 \mathrm{~h}$ compared with the parental peaks at $08.00 \mathrm{e} 09.00 \mathrm{~h}$ for $\mathrm{S}$. bovis and $13.00 \mathrm{e} 14.00 \mathrm{~h}$ for S. haematobium (Figure 8). 


\subsubsection{Hybridization between S. haematobium and S. intercalatum (Pages and Théron, 1990a,b)}

The two parental species have a single emergence peak with quite the same time position between 13.00 and $14.00 \mathrm{~h}$. Hybrid schistosomes (F1) resulting from this cross show an emergence pattern with a peak emission earliest than the parental ones, between 11.00 and 12.00 h (Figure 8).

To summarize, within the lateral egg-spined group of schistosomes, inter-specific crossings gave individuals with cercarial emergence phenotypes intermediate between the parents or with two peaks corresponding of the parental ones. One could envisage that difference between homopatric strains results from allelic variation at the same locus while differences between heteropatric strains or between species may concern different genes. In contrast all the results from hybridizations between species of Schistosoma from the terminal egg-spined group demonstrated that hybrid parasites have a cercarial shedding pattern with a peak emergence always more early than that of the earliest parent. The absence of a structured cercarial emergence birth pore on the sporocysts of the terminal-egg-spined species (while present for sporocysts of the S. mansoni group) may be involved in this phenomenon (see Section 3.3).

If there is no doubt that cercarial emergence patterns are genetically based, results obtained illustrate the complexity of the phenomenon and the necessity of more investigations including the analysis on several consecutive generations and back-cross experiments to a better understanding of the genes implicated and the epigenetic processes which probably intervene on the phenotypes observed.

\section{6- Epidemiological applications}

For trematode infections of medical or veterinary importance (e.g. human and bovine schistosomes or birds schistosomes causing swimmer's itch), chronobiology of cercarial emergence is one of the main factors affecting the definitive host infection risk since daily variations of cercarial densities in the water are in part greatly influenced by the shedding rhythms (in other part by distribution and density of infected snails and water features). Cercariometry provides information on daily, seasonal and spatial fluctuations of cercarial densities in natural water bodies (Théron, 1986a; Muhoho et al., 1997; Kimura et al., 1994; Aoki et al., 2003).

\subsection{Cercariometry}

Techniques for the detection of cercariae in the water of transmission sites and for the evaluation of their densities (cercariometry) have been greatly improved (see Théron, 1986a for review). From the various techniques proposed (Barret and Ellison, 1965; Buttler et al., 1967; Klock, 1961; Olivier, 1966; Sandt, 1972, 1973), actually the most performant apparatuses are based on a differential filtration of water samples taken out from water bodies and the recovery and staining of the cercariae trapped on the last filter (Figure 9). Compared to original apparatus first developed by Rowan (1957), the main innovation concerns the use of a new category of reusable polyamide filters (Théron, 1979) for which exists a large range of pore sizes. This recovery 


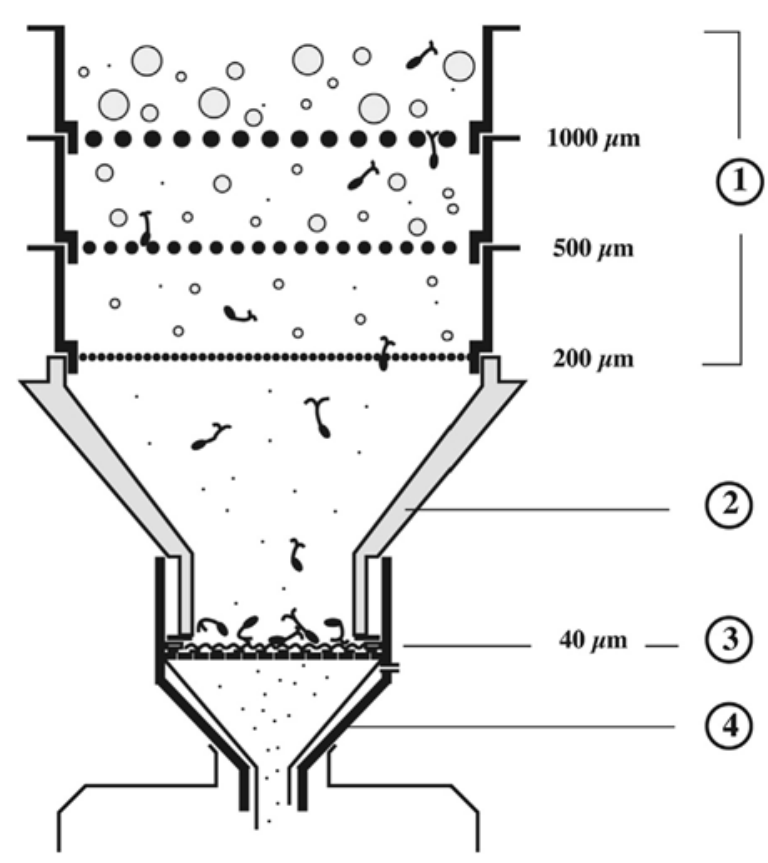

Figure 9 Schematic cross section of the differential filtration apparatus for the measure of cercarial densities in the water: (1) Pre-filtration column with decreasing pore size steel sieves; (2) connecting piece, (3) recovery polyamide filter, and (4) filter support. Modified from Théron (1986a).

filter is placed under a pre-filtration column with a series of steel sieves of decreasing pore size. Pore size of the recovery filter (between 20 and $45 \mathrm{~mm}$ ) can be chosen as a function of the size of the cercariae and the turbidity of the water. This technique allows the filtration of water samples more than $10 \mathrm{~L}$, requires no power supply and can be easily used in the field with recovery rates greater than $80 \%$ even in waters with some concentration of microorganisms (Kloos et al., 1982; Théron, 1989).

\subsection{Rhythms of cercarial densities}

In the laboratory, cercarial shedding rhythms are detected and analyzed immediately when the cercariae leave the snail host and before their dispersion in an aquatic environment. How this shedding rhythm affects the variations of the cercarial densities in natural waters? Two main factors may influence the daily variations of cercarial densities in the water: (1) the spatial distribution of the infected snails, (2) the hydrodynamic features at the transmission site.

- In running water transmission sites, emitted cercariae are for the majority of them driven in the same direction by the water flow. Measurement on a 24-h period of the cercarial densities showed that the hourly density variations along a canal, for example, are directly correlated with the cercarial shedding pattern. Maximum cercarial densities in the water occurs at the same time that the peak emergence from the snails (Théron et al., 1977). The spatial heterogeneity of the infected snail distribution influences the quantity of cercariae per litre but does not modify the time variations if the current is up to $0.05 \mathrm{~m} / \mathrm{s}$ (Figure $10(\mathrm{a}))$. 
- In standing water transmission sites, the daily variations of cercarial densities are less easy to predict since numerous factors (active swimming, phototactism, accumulative processes, drift of cercariae) can influence the spatial dispersion of the cercariae. However, it appears that in standing water or in very low water flow, the rhythm of cercarial densities is always delayed compared with the rhythm of emergence from the snails. The maximum cercarial densities can occur several hours after the peak emergence (Figure 10(b)). Spatial heterogeneity of the infected snails can induce modifications of the density versus emergence rhythm and several peaks of cercarial density can be detected (Théron et al., 1977).

6.3 Detection and control of transmission sites

To detect the positivity of schistosomiasis transmission sites by cercariometry the simple recovery of cercariae in the water will be sufficient. Evidently the 


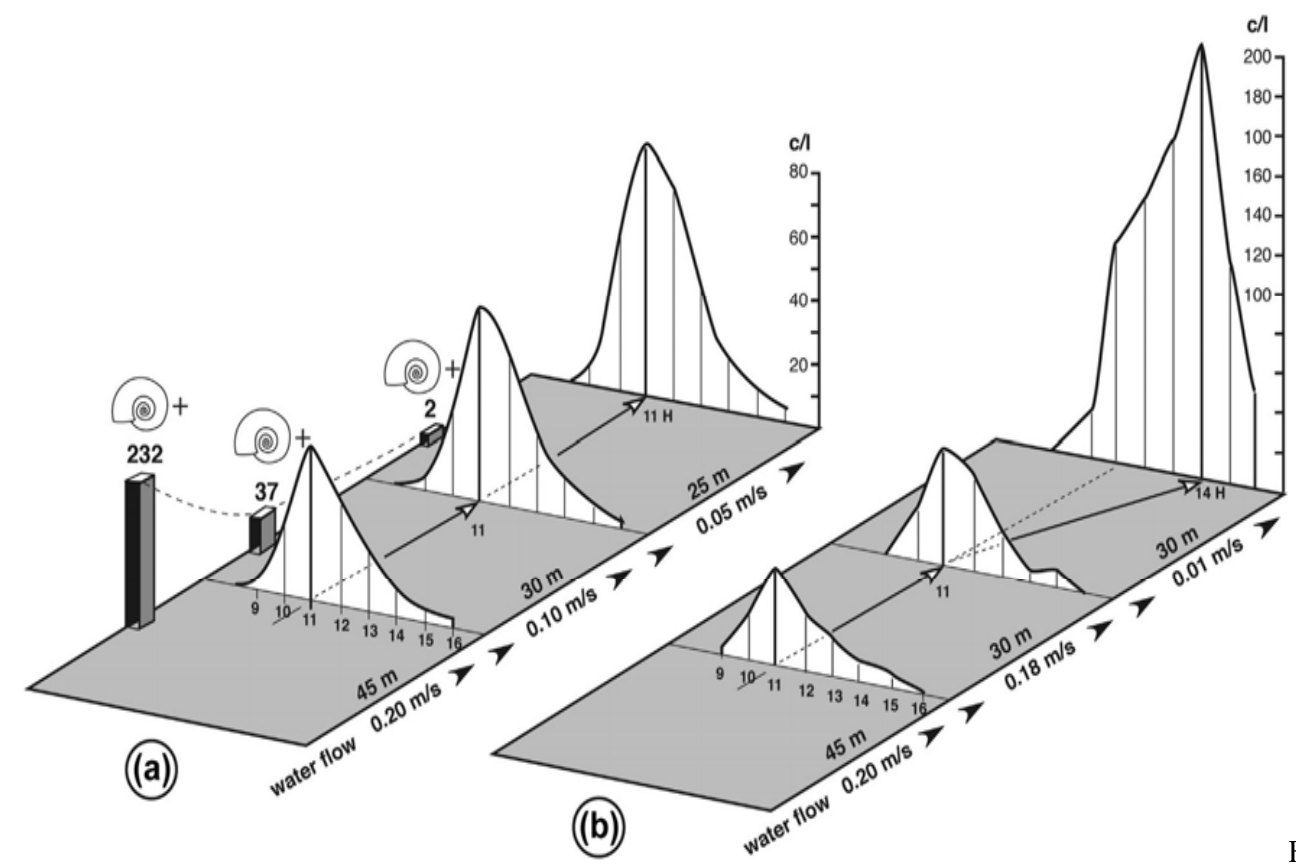

Figure 10 Hourly variations of the cercarial densities ( $\mathrm{c} / \mathrm{l}$ : cercariae per litre) of Schistosoma mansoni within a canal with running water. (a) Note that a moderate reduction of the water flow (from 0.20 to $0.05 \mathrm{~m} / \mathrm{s}$ ) results in an increase of the cercarial densities in the water but without modification of the peak time $(11.00 \mathrm{~h}) \mathrm{dBars}$ : number of infected snails within a sector; (b) When the water flow is highly reduced $(0.01 \mathrm{~m} / \mathrm{s})$ accumulation of cercariae in the almost standing water deletes the maximal densities of cercariae at $14.00 \mathrm{~h}$. Adapted from Théron (1982). 
sensibility of the method will be greatly enhanced if sampling of the water is carried out during the periods of the day corresponding with maximal cercarial densities. A good knowledge of the cercarial emergence rhythm of the species of parasite studied (and sometimes rhythm of the population of the parasite concerned) is then necessary for the epidemiological survey. This approach has allowed the detection of transmission sites by recovery of cercariae in water bodies where detection of infected snails was unsuccessful because of their low prevalence (Pointier et al., 1984).

To control transmission sites by cercariometry, the quantitative evaluation of the cercarial densities will be performed in such conditions that results should be significantly compared independently of the season of the year considered and the particularity of the transmission site (variation of the water flow). Théron (1980b) proposed to estimate in running water transmission sites, the Daily Cercarial Drift (DCD) measured at different selected points of a channel. The DCD (expressed in cercariae per day) is given by the product of the daily sum of hourly densities (cercariae per litre) and the water flow $(\mathrm{L} / \mathrm{h})$. The daily sum of hourly densities can be evaluated from a single daily sample which allows several sites to be monitored each day. Transferred to a hydrographical network map (Figure 11), cercariometric data, showing the spatial and seasonal variations of the cercarial densities, can be established giving an overview of the potential infection risk for humans or the efficiency of a control program on snail populations or human communities.

\subsection{Identification of snail infection}

A single species of snail may act as intermediate host for several different species of trematode and some times, the absence of any morphological difference among the cercariae shedded renders difficult the identification of the snail infection. As an example, in some Sahelian pools it is common to find S. haematobium, S. bovis and S. curassoni transmitted by the same snail host species (Bulinus umbilicatus) in the same water bodies. In this condition, a simplified test for the rough determination of the maximal shedding period easily can provide a distinction between species (Mouchet et al., 1992). These chronobiological differences may improve epidemiological surveys based on snail prevalences by allowing the distinction between bulinids infected with bovine (early morning emergence) or human (middle day emergence) parasites. More recently, the detection of DNA sequences by PCR is a useful typing tool for species identification of cercariae emerging 

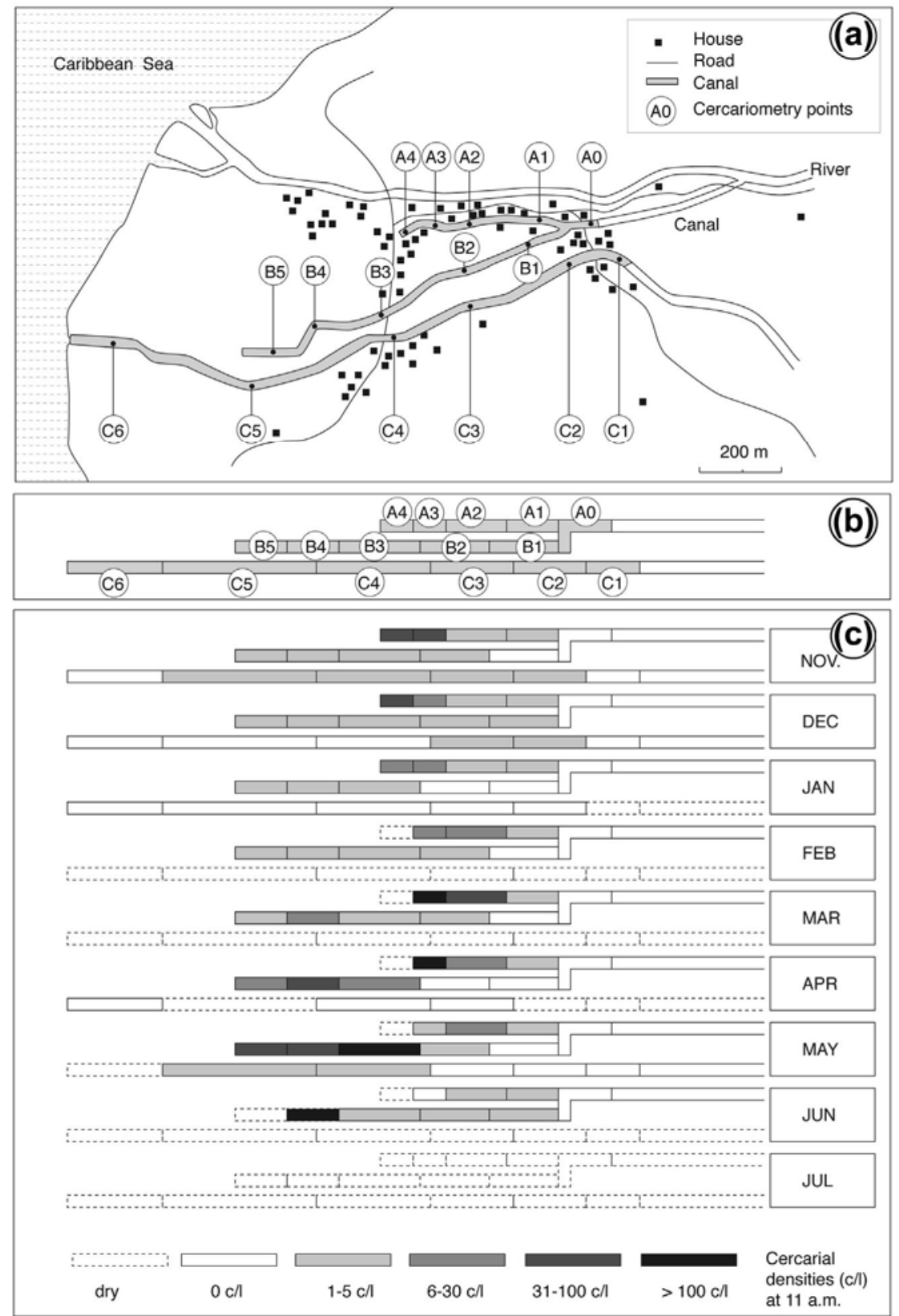

Figure 11 Hydrogeographical network at the village of Marigot-Beaugendre in Guadeloupe (a) with the location of different cercariometry points along the three canals (b) and the results of the variations of cercarial densities (c/l) during 9 months of survey with different water flow conditions (c). 
from naturally infected snail from field studies and monitoring transmission sites (Abath et al., 2006; Standley and Stothard, 2012).

\section{7- Population biology}

\subsection{Inter- and intra-specific chronobiological diversity}

Inter-specific diversity of the emergence patterns of trematode cercariae may occur at three levels: (1) the existence/absence of a rhythm; (2) the type of rhythm and (3) for a given type of rhythm, the position of the peak emergence during a day/night cycle. An absence of rhythmicity has been reported mainly for cercariae that encyst in the external medium (Figure 12(a)) as for Fasciola hepatica (Kendall and McCullough, 1951; BouixBusson et al., 1985) which cercariae are shed continually from the snail host without particular period of high emission.

However, the majority of the species of trematodes which have been studied for their cercarial chronobiology patterns are rhythmic and principally of the circadian type (i.e. one peak of emission during a 24-h period, Figure 12(c)). Few species show cercarial rhythms of the ultradian type (i.e. two peaks of emission during a 24-h period as it is the case for Schistosoma margrebowiei (Raymond and Probert, 1991) (Figure 12(b))). Species with circadian rhythmicity show emergence peak that can take place at different times of the day or night period as well as at dawn or dusk. Cercariae of the Schistosoma genus gave a demonstrative illustration of this chronobiological diversity since emergence peaks of the different species are positioned all along the 24-h period (Figure 13).

Few studies have been devoted to the intra-specific polymorphism of cercarial emergence patterns and, in our knowledge, this was only demonstrated for three species of schistosomes, S. mansoni (Théron, 1984, 1985; Mouahid et al., 2012), S. haematobium (Kechemir and Théron, 1997; N'Goran et al., 1997) and S. japonicum (Lu et al., 2009) whose populations from a same endemic area showed different patterns of cercarial emergence.

\subsection{Chronobiological diversity and its ecological significance}

The main consequence of the cercarial rhythmicity is to concentrate, in the aquatic environment, the maximum number of cercariae at a particular period of the day. Because in many cases, this time localization of the parasite is correlated with the presence or with the activity period of the host in this environment (e.g. schistosomes, Figure 13), cercarial chronobiology was empirically considered as an adaptive behaviour favouring the parasite transmission (see Combes et al., 1994) by increasing the meeting probabilities between the parasite and its host. One can easily understand that a shortlived cercariae, which have developed morphological ornaments to attract its host predator, will have more "chance" to be eaten by a fish if its emergence from the snail coincides with the feeding activity period of the fish. This is the case of Proterotrema edneyi, a large swimming cercariae emerging during the light period and predated by fishes which feed diurnally (Lewis et al., 1989). Another particularly convincing example was given by the inter-populational chronobiological diversity of S. mansoni demonstrated in field conditions and related to the diversity of hosts species involved in the transmission dynamics. Briefly summarized 
(see Théron and Pointier, 1995 for a review), in a little island of the Caribbean sea (Guadeloupe) which is an endemic focus of the intestinal schistosomiasis, the parasite, S. mansoni develops into two different definitive hosts, human and rats (Rattus rattus). However, the relative infection rates of the two hosts differs according to the ecological diversity of the transmission areas (Figure 14): at the urbanized foci in valleys of the western coast of the island, human were heavily infected while rats were found parasitized only occasionally; at the sylvatic mountain foci, human do not participate in the transmission and rats were the only host for the parasite. An intermediate situation occurred at the swampy foci of the eastern island where human and rats were similarly infected. Chronobiological studies on the cercariae of schistosomes originating from these different foci and from the two hosts showed that the parasite has selected different cercarial emergence phenotypes adapted to the main host species. Early emergences characterize schistosomes using human as main definitive host while late emergences of the cercariae characterize the schistosome populations of the sylvatic focus using rat as definitive host and which behaviour is essentially crepuscular or nocturnal. Interesting was the situation of the swampy foci where a chronobiological polymorphism was locally maintained with early and late emergence patterns adapted to the two hosts respectively, but also the existence of intermediate phenotypes resulting from the cross between schistosomes of the two host-adapted populations of parasite, that of the human strain and that of the murine strain (experimentally demonstrated; see Section 5.1). In Oman, where the rat R. rattus is also found parasitized by S. mansoni, a strictly nocturnal chronotype was recently described (Mouahid et al., 2012). 

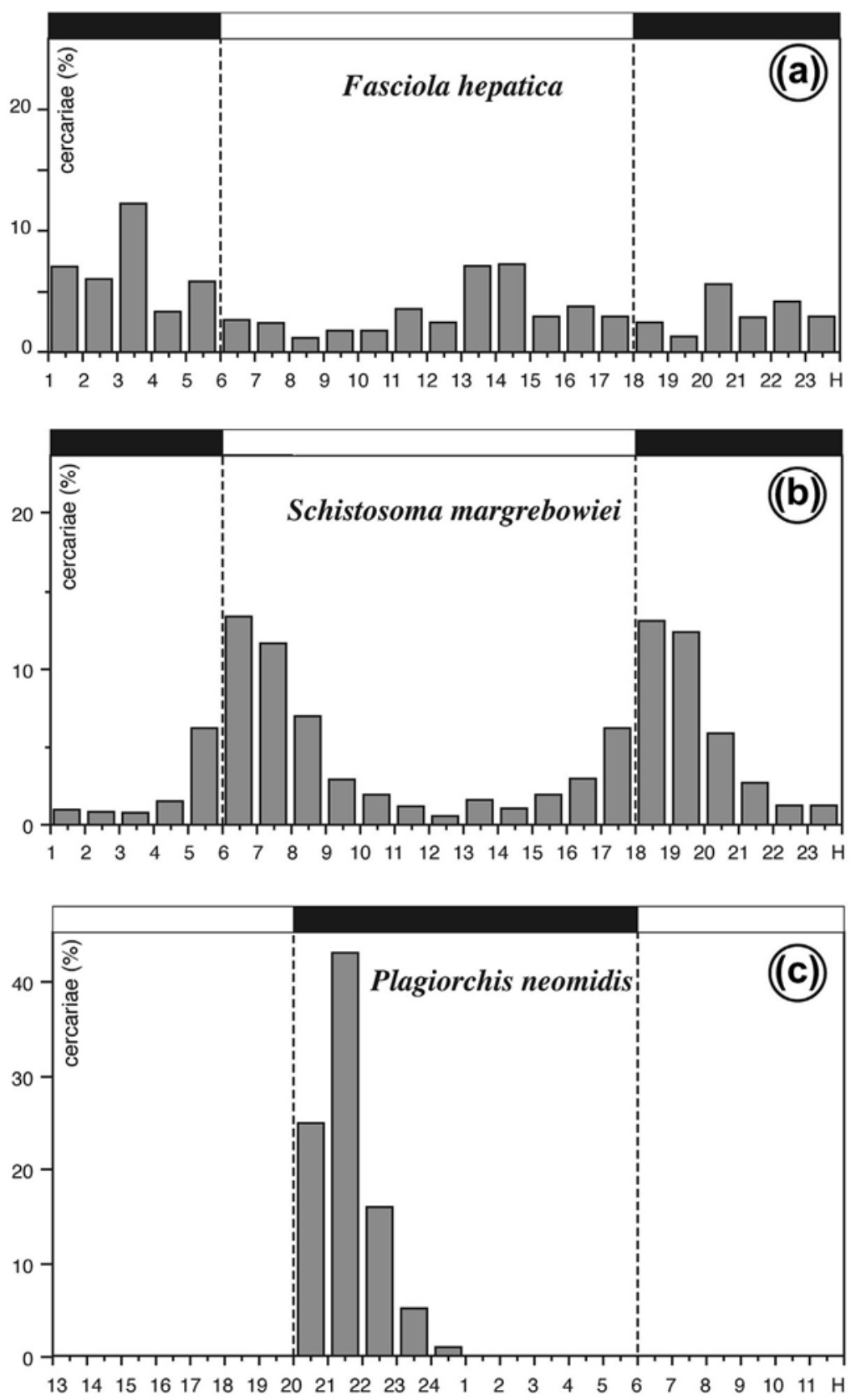

Figure 12 Inter-specific diversity of the cercarial shedding patterns of digeneans: (a) absence of rhythmic emergence for Fasciola hepatica cercariae; (b) ultradian rhythm with two peaks of emission at dawn and dusk for Schistosoma margrebowei; (c) circadian 
rhythm with a nocturnal peak for the cercariae of Plagiorchis neomis. Modified from Bouix-Busson et al. (1985), Raymond and Probert (1991), Théron (1976).

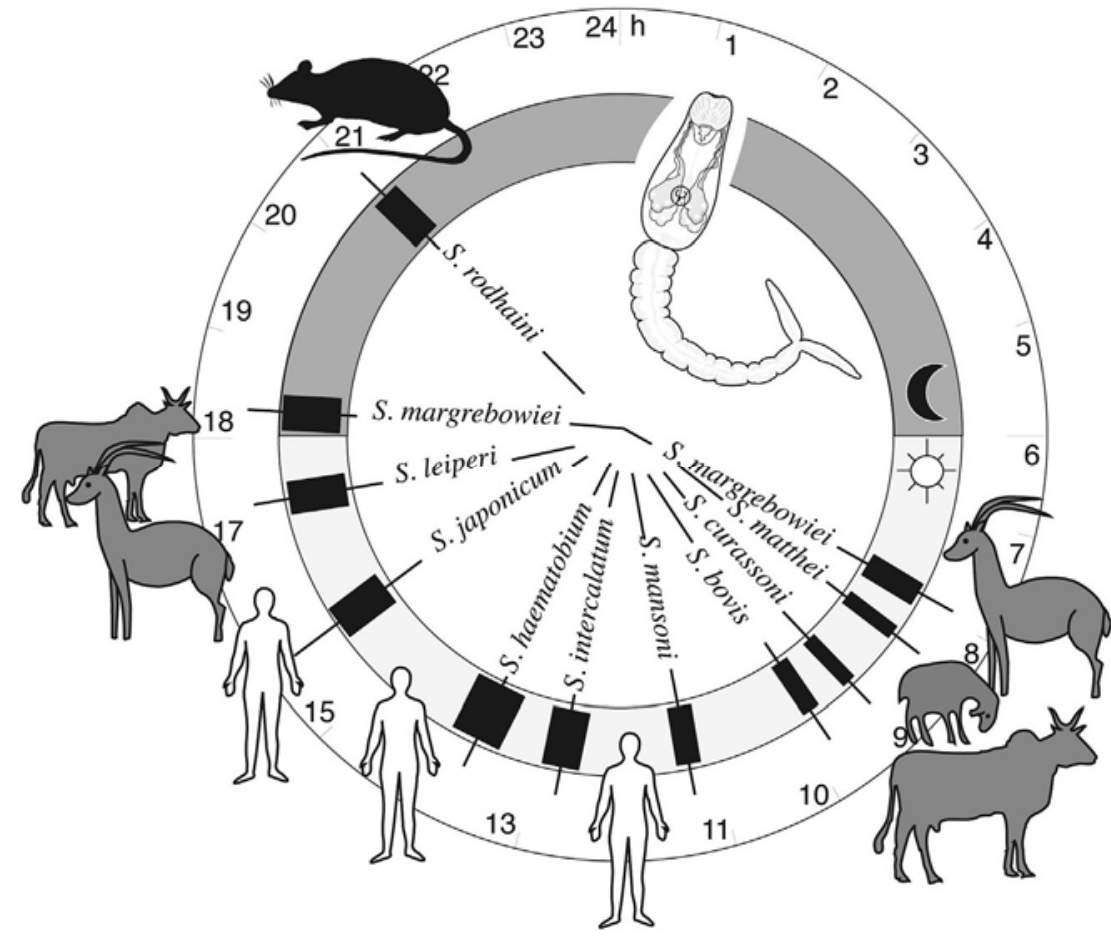

Figure 13 The cercarial clock of schistosomes. Inter-specific diversity of the cercarial chronobiology is particularly well illustrated among the various species of Schistosoma which exhibit peak emergences from dawn to dusk with only one species (S. rodhaini) with a nocturnal shedding pattern. The corresponding definitive hosts are recalled as an example of the correlation between the diversity of the rhythms and the diversity of the behaviours of the host species.

In China, S. japonicum populations from the hill region in Anhui display a late afternoon cercarial emergence compatible with a nocturnal rodent reservoir while those from the marshland region show an early pattern consistent with a diurnal cattle reservoir ( $\mathrm{Lu}$ et al., 2009; Su et al., 2013).

In Africa, N'Goran et al. (1997) have shown that intra-specific chronobiological diversity can also occur in the absence of different definitive hosts implicated in the parasite transmission. This concerns $\mathrm{S}$. haematobium, a parasite strictly specific of humans. In Ivory Coast (Africa), chronobiological patterns of cercarial emergence change between populations sampled along a NortheSouth line with mean shedding times decreasing significantly from the North to the South (Figure 15). This chronobiological diversity, 
independent from the species of Bulinus snails (B. globosus and B. truncatus) implicated in the transmission dynamics was correlated with the climatic and vegetal features of the transmission areas. S. haematobium populations 


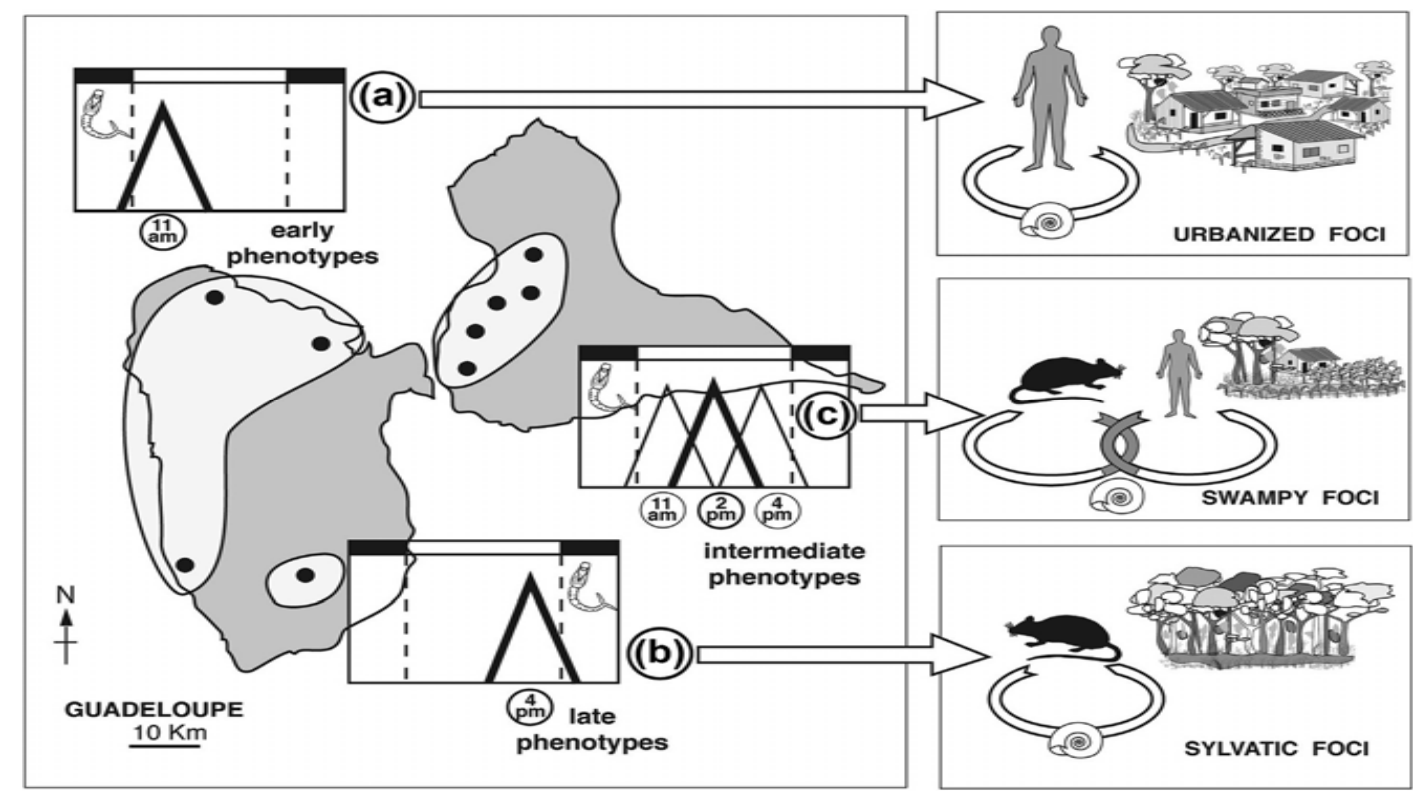

Figure 14 Intra-specific polymorphism of the cercarial shedding patterns of Schistosoma mansoni from the Guadeloupe Island. (a) Early phenotypes characterize schistosome populations from urbanized foci where man is the principal host; (b) Late phenotypes characterize schistosome populations from sylvatic foci where rats are the only host; (c) early, late and intermediate phenotypes are encountered within the swampy foci where human and rat are together involved in the transmission dynamics. 


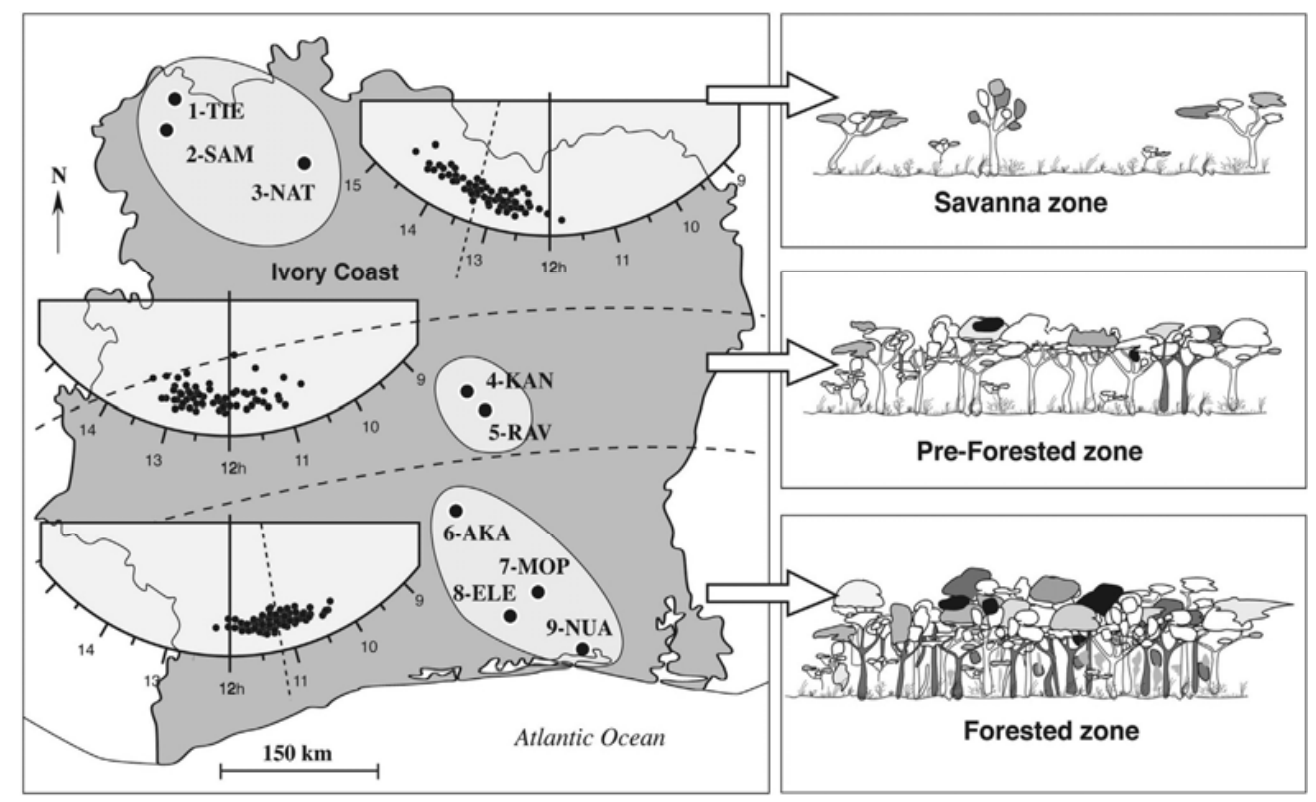

Figure 15 Intra-specific chronobiological polymorphism among nine populations of Schistosoma haematobium from Ivory Coast (Africa). Cercarial shedding patterns change between populations sampled along a NortheSouth line with mean shedding times decreasing significantly from the North to the South. This chronobiological diversity was correlated with the climatic and vegetal features of the transmission areas, traducing differences in sensitivity to light intensity in relation to the shadow response characteristic of this species. Modified from N'Goran et al. (1997). 
from the Guinean climatic zone with shaded transmission sites located in the dense rain forest (South) showed cercarial emergence patterns significantly earliest than that of S. haematobium populations from the sub-Sudanian zone with open transmission sites in the Savanna (North) (Figure 15). Taking into account these results, one can assume that S. haematobium cercariae from the forest shaded sites will be more sensitive to low illumination than $\mathrm{S}$. haematobium cercariae from the Savanna where open transmission sites are directly exposed to high illumination. These differences in sensitivity to light intensity could characterize the existence of ecogeographical races of S. haematobium one from the forest, the other from the Savanna. In contrast to $\mathrm{S}$. mansoni, cercarial emergence of $\mathrm{S}$. haematobium showed rapid reaction to variations in light intensity (Raymond and Probert, 1987) and a "shadow response" (i.e. stimulation of cercarial emergence from snails by human activity making shadow on the water) was described for this species as a process able to increase the risk of infection (Noda et al., 1986). The differential sensibility to light between Savanna and forest strains of parasite could be viewed as an ecological adaptation for maintaining the "shadow response" of the cercariae even in forest transmission sites with low illumination conditions.

However, as it has been pertinently discussed by Shostack and Esch (1990), other selective forces than presence/absence of the potential host may be implicated in the selection of chronobiological phenotypes. Periodicity can be also viewed as a process that enhances cercarial dispersion relative to some aspects of the snail movements or location or physical factors of the environment (Lowenberger and Rau, 1994). Another alternative is that periodicity reduces mortality through predator avoidance. For Proterometra macrostoma, the nocturnal shedding of cercariae is suspected to be an adaptation decreasing susceptibility of cercariae to predation by diurnal feeding non-host fishes (Lewis et al., 1989).

\section{8-Evolutionary Biology}

\subsection{Host spectrum and lateral transfers between}

Theoretically, the establishment of a hosteparasite system needs three main conditions: (1) the parasite and its potential host have to encounter each other (meeting filter), (2) the parasite has to be immunologically accepted by the host (compatibility filter), and (3) the host must furnish an adequate physiological environment for the parasite development and reproduction (suitability filter). The number of animal species which satisfies to these three conditions constitutes the host spectrum for the species of parasite considered (Combes, 1995).

The meeting filter has two components, a spatial one and a temporal one (to meet each other, host and parasite have to be at a same place, at the same time). Then, the time localization of the trematode cercariae due to their chronobiological behaviour may play a significant role at the level of the meeting filter. As an example, man who is a potential host for S. rodhaini (a parasite of rodents in Central Africa) is rarely naturally infected by this species of schistosome (however, see Morgan et al., 2003; Steinauer et al., 2008). In this case, the compatibility as well as the suitability filters are open but the meeting filter remains closed because the asynchrony between the diurnal behaviour of man and the strictly nocturnal shedding of the S. rodhaini cercariae. On the opposite way, changes in the chronobiological pattern of cercariae may 
contribute to host diversification by lateral transfer (Théron and Combes, 1995). This seems to be what has happened for the human parasite S. mansoni in the island of Guadeloupe which is actually found with high prevalence and intensity among the nocturnal black rat, R. rattus (Théron et al., 1992). The capture of this murine host (whose compatibility and suitability filters were open) was probably strongly facilitated by the selection of late chronobiological phenotypes of cercariae (Figure 16(a) and (b)). As previously described (see Section 7.2) in areas where man and rat are infected, S. mansoni populations maintain sympatrically a balanced polymorphism with early and late chronobiological phenotypes favouring diurnal infection of humans and crepuscular infection of rats respectively.

\subsection{Host preference and sympatric speciation}

Inter-populational cercarial emergence diversity, as in the case of the model S. mansoni/man/rat in Guadeloupe, was considered as a sufficient mechanism to both initiate and maintain restricted gene flow between the two host-adapted populations of schistosomes (Théron and Combes, 1995), considering that early and late chronobiologies of cercariae determine a host habitat preference towards man or rat respectively. The by-product of this habitat choice is the establishment of a positive assortative mating system with early-emerging schistosomes tending to return and reproduce together in a human host and late-emerging schistosomes tending to return and reproduce together in a murine host (Figure 16(c)). In this case, the asynchrony of infection timing acts as an effective mechanism in the genetic 


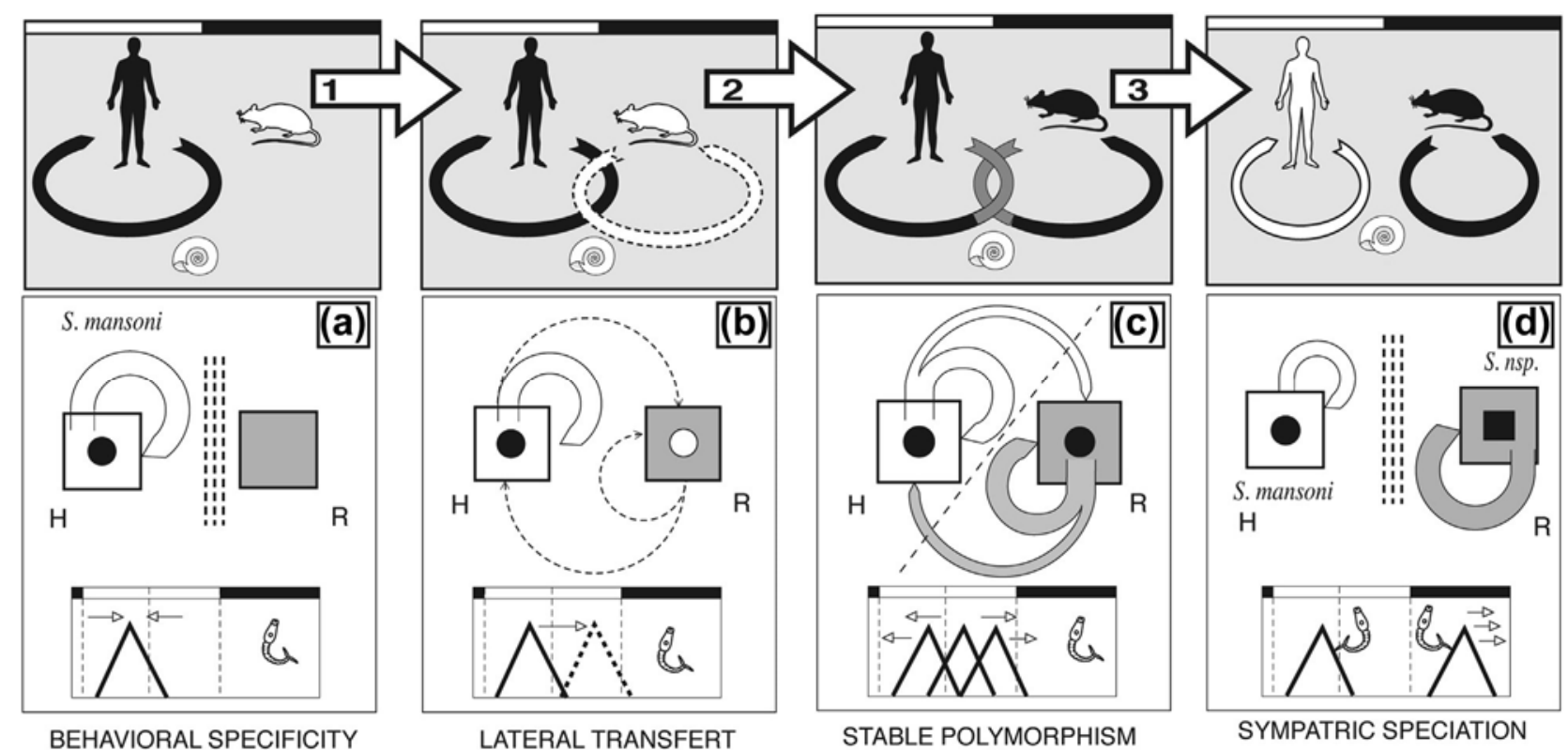

Figure 16 Schistosoma mansoni sympatric speciation model through host diversification and habitat selection. (a) When introduced by man in Guadeloupe, less than 400 years ago, early chronobiological phenotype of cercariae maintains specificity of the parasite to human hosts (H). (b) A mutation affecting the gene controlling the timing of cercarial shedding (late emergence) allows the capture of the human schistosome by a rodent host, Rattus rattus (R) with crepuscular behaviour. (c) Establishment of a stable polymorphism among S. mansoni populations confronted with a heterogeneous environment (human and murine hosts). When asynchrony of timing infection are sufficiently marked, restriction of the 
gene flow by habitat choice and positive assortative mating of worms leads to the formation of host races of schistosomes. (d) An eventually complete isolation can occur with a strictly nocturnal shedding of infective larvae, allowing sympatric speciation with the emergence of a new species of murine schistosome. (Early, intermediate and late shedding curves of cercariae are showed in reference to a day/night cycle; dynamics of the parasite transmission towards human and/or murine hosts are indicated). 
isolation between the two host-adapted populations. A more efficient reproductive barrier would be obtained if the mutation affecting the gene that controls timing differences led to a strictly nocturnal emission of the murine strain of schistosomes as in the case of S. mansoni populations from Oman (Mouahid et al., 2012). This will contribute to an increasing degree of differentiation and reinforce the potentiality of sympatric speciation (Figure 16(d)).

This example clearly shows that when genetic divergence affects the behaviour of infective larvae, such as cercarial shedding rhythms involved in the acquisition of host resources, the emergence of new host races of parasite may require only minor alteration in the genome and selection of adaptive traits may then occur in a small number generations.

\section{9- Concluding remarks}

Biological clocks allow organisms to synchronize their activities with the predictable cycle of day and night, giving them a sense of time. For free and short living stages of trematodes, such as the cercariae, giving a sense of time looks principally to make coincident the period of the day at which the potential hosts are present and accessible for the parasite. It should be also to ovoid the period at which the risk of predation by a nonhost organism is the highest. In both cases, cercarial shedding behaviours have been selected to maximize the transmission of parasite genes from one host to the next host. However, in some cases the selective advantage of a biological rhythm remains to be clarified. This is the case for non-motile and long lived cercariae which can survive several months in the water as in the case of the nocturnal emergence of Halipegus occidualis (Shostak and Esch, 1990). Other aspects which merit to be explored should be to investigate at the level of the dynamics of the cercarial maturation inside the sporocysts/ rediae, the step just before the exit of the cercariae. Some basic aspects have been studied in the past, as the ontogeny of the cercariae from the germinal cells to the mature cercariae (see Cheng and Bier, 1972; Schutte, 1974) or the dynamics of the intra-sporocystic cercarial production which exhibits for some species an infradian rhythm of production relative to different successive generations of intra-sporocystic cercariae (Théron, 1981a,b). As previously discussed, cercarial sheddings are typically populational rhythms but this rhythmicity is probably governed by an oscillator that dictates successive "allowed zones" or "gates" through which the cercariae can emerge after they have achieved their complete development. Nothing is known concerning the physiological processes responsible for the transition between the inactive cercariae within the sporocyst/rediae and the mature cercariae ready to move and to leave out of the sporocyst/rediae and, later out of the snail. What kind of regulatory process governs, each day within the sporocysts or the rediae, the number of cercariae which will emerge to ovoid a surplus of mature cercariae in the snail?

Concerning processes and mechanisms involved, it is now well understood that variations of shedding patterns are genetically controlled, however, it remains to be demonstrated what gene systems are involved. Analysis of the genetic and molecular basis of a behavioural pattern has been particularly well investigated in other organisms such as 
in Drosophila melanogaster with at least six different genes known to affect circadian rhythms of this insect. The period per locus of D. melanogaster, discovered by Konopka and Benzer (1971), is one of the best studied "behavioural genes" in any organism. Mutation of the per gene abolishes completely all circadian behaviour, not only the hatching rhythm but also the rhythm of spontaneous locomotor activity of adult flies. Other mutations of this gene can increase or decrease the period of the rhythm. Homologous sequences of the per gene of Drosophila have been recovered within the DNA of various other animal and vegetal organisms (Blau et al., 2014). Such a piece of work would be likely to be developed with respect to cercarial emergence patterns of digeneans. While ecological significance and possible evolutionary implications of cercarial shedding diversity have been well illustrated during this last years, we need now to better understand physiological, cellular and molecular processes implicated in the cercarial clock of digeneans. Genome sequence data now available for some trematodes such as schistosomes, in combination with genetic crosses between chronobiological variants and linkage mapping, may provide an exciting opportunity that should allow identification of the genes and mechanisms involved in determining the circadian patterns observed.

\section{REFERENCES}

Abath, F.G., Gomes, A.L., Melo, F.L., Barbosa, C.S., Werkhauser, R.P., 2006. Molecular approaches for the detection of Schistosoma mansoni: possible applications in the detection of snail infection, monitoring of transmission sites, and diagnosis of human infection. Mem. Inst. Oswaldo Cruz 101, 145e148.

Anderson, P., Nowosielski, J., Croll, N., 1976. The emergence of cercariae of Trichobilharzia ocellata and its relationship to the activity of its snail host Lymnaea stagnalis. Can. J. Zool. 54, 1481e1487.

Aoki, Y., Sato, K., Muhoho, N.D., Noda, S., Kimura, E., 2003. Cercariometry for detection of transmission sites for schistosomiasis. Parasitol. Int. 52, 403e 408.

Asch, H.L., 1972. Rhythmic emergence of Schistosoma mansoni cercariae from Biomphalaria glabrata: control by illumination. Exp. Parasitol. 31, 189e198.

Aschoff, J., 1960. Exogenous and endogenous components of circadian rhythms. Cold Spring Harb. Symp. Quant. Biol. 25, 11e28.

Barret, P.D., Ellison, P.R., 1965. A continuous flow centrifuge for testing the presence of bilharzia cercariae in water. Cent. Afr. J. Med. 11, 338e340.

Batschelet, E., 1981. In: Sibson, R., Cohen, J.E. (Eds.), Circular Statistics in Biology. Academic Press. Inc, London, $371 \mathrm{pp}$.

Bingham, C., Arbogast, B., Cornélissen, G., Lee, J.-K., Halberg, F., 1982. Inferential statistical methods for estimating and comparing cosinor parameters. Chronobiologia 9, 397e439.

Blau, J., Blanchard, F., Collins, B., Dahdal, D., Knowles, A., Mizrak, D., Ruben, M., 2014. What is there left to learn about the Drosophila clock? Cold Spring Harb. Symp. Quant. Biol. 72, 243e250.

Bogéa, T., Favre, T.C., Rotenberg, L., Silva, H.S., 1990. Chronobiological aspects in the emission of Schistosoma mansoni cercariae from Biomphalaria glabrata spp. under outdoor conditions: mono- and plurimiracidial infections. J. Interdiscip. Cycle Res. 21, $171 \mathrm{e} 173$. 
Bogéa, T., Favre, T.C., Rotenberg, L., Silva, H.S., Pieri, O.S., 1996. Circadian pattern of cercarial emergence in Schistosoma mansoni (Platyhelminthes: Digenea) from isolated Biomphalaria glabrata. Chronobiol. Int. 13, 93e101.

Bouix-Busson, D., Rondelaud, D., Combes, C., 1985. L'infestation de Lymnaea glabra Muller€ par Fasciola hepatica L. Les caractéristiques des émissions cercariennes. Ann. Parasitol. Hum. Comp. 60, 11e21.

Buttler, J.M., Ruiz-Tiben, E., Ferguson, R., 1967. New field device for quantitative recovery of Schistosoma mansoni cercariae. Pub. Health Rep. 82, 250e252.

Chassé, J.L., Théron, A., 1988. An example of circular statistics in chronobiological studies: analysis of polymorphism in the emergence rhythms of Schistosoma mansoni cercariae. Chronobiol. Int. 5, 433e439.

Cheng, T.C., Bier, J.W., 1972. Studies on molluscan schistosomiasis: an analysis of the development of cercaria of Schistosoma mansoni. Parasitology 64, 129e141.

Combes, C., 1995. Interactions durables: écologie et évolution du parasitisme. Masson, Paris, 524 pp.

Combes, C., Fournier, A., Moné, H., Théron, A., 1994. Behaviors in trematode cercariae that enhance parasite transmission: patterns and processes. Parasitology 109, S3eS13.

Disko, R., 1978. An automatic method for recording the emergence of cercariae of Schistosoma mansoni from the snail Biomphalaria glabrata. Z. Parasitenkd 155, $235 \mathrm{e} 239$.

Fournier, A., Théron, A., 1985. Sectorisation morpho-antomique et fonctionnelle du sporocyste fils de Schistosoma mansoni. Z. Parasitenkd 71, 325e336.

Giovannola, A., 1936. Some observations on the emission of cercariae of Schistosoma mansoni (Trematoda: Schistosomatidae) from Australorbis glabratus. Proc. Helminthol. Soc. Wash. 3, 60e61.

Glaudel, R.J., Etges, F.G., 1973. The effect of photoperiod inversion upon Schistosoma mansoni cercarial emergence from Biomphalaria glabrata. Int. J. Parasitol. 3, 619e621.

Halberg, F., Carandente, F., Cornélissen, G., Katinas, G.S., 1977. Glossary of chronobiology. 1982. Chronobiologia 4, 1e190.

Hawking, F., 1975. Circadian and other rhythms of parasites. Adv. Parasitol. 13, 123e182.

Jourdane, J., Théron, A., 1980. Schistosoma mansoni: cloning by microsurgical transplantation of sporocysts. Exp. Parasitol. 50, 349e355.

Kazibwe, F., Makanga, B., Rubaire-Akiiki, C., Ouma, J., Kariuki, C., Kabatereine, N.B., Vennervald, B.J., Rollinson, D., Stothard, J.R., 2010. Transmission studies of intestinal schistosomiasis in Lake Albert, Uganda and experimental compatibility of local Biomphalaria spp. Parasitol. Int. 59, 49e53.

Kechemir, N., Théron, A., 1997. Intraspecific variations of Schistosoma haematobium from Algeria. J. Helminthol. 71, 29e33.

Kendall, S.B., McCullough, F., 1951. The emergence of cercariae of Fasciola hepatica from the snail Lymnaea truncatula. J. Helminthol. 27, 77e92.

Kimura, E., Uga, S., Migwi, D.K., Mutua, W.R., Kiliku, F.M., Muhoho, N.D., 1994. Hourly change in cercarial densities of Schistosoma haematobium and S. bovis at different depths in the water and distances from the shore of a dam in Kwale District, Kenya. Trop. Med. Parasitol. 45, 112e114.

Klock, J.W., 1961. A method for the direct quantitative recovery of Schistosoma mansoni cercariae from natural waters of Puerto Rico. Bull. World Health Organ. 25, 738e 740.

Kloos, H., Gardiner, C.H., Selim, A., Higashi, G.,I., 1982. Laboratory and field evaluation of a direct filtration technique for recovery of schistosome cercariae. Am. J. Trop. Med. Hyg. 31, 122e127. 
Konopka, R.J., Benzer, S., 1971. Clock mutants of Drosophila melanogaster. Proc. Natl. Acad. Sci. U.S.A. 68, 2112e2116.

Kuntz, R.E., 1947. Effect on light and temperature on emergence of Schistosoma mansoni cercariae. T. Am. Microsc. Soc. 66, 37e49.

Lewis, M.C., Welsford, I.G., Uglem, G.L., 1989. Cercarial emergence of Proterotrema macrostoma and P. edneyi (Digenea: Azygiidae): contrasting response to light:dark cycling. Parasitology 99, $215 \mathrm{e} 223$.

Lowenberger, C.A., Rau, M.E., 1994. Plagiorchis elegans: emergence, longevity and infectivity of cercariae, and host behavioural modifications during cercarial emergence. Parasitology 109, 65e 72.

Lu, D.B., Wang, T.P., Rudge, J.W., Donnelly, C.A., Fang, G.R., Webster, J.P., 2009. Evolution in a multi-host parasite: chronobiological circadian rhythm and population genetics of Schistosoma japonicum cercariae indicates contrasting definitive host reservoirs by habitat. Int. J. Parasitol. 14, 1581e1588.

Luttermoser, G., 1955. Studies on the chemotherapy of experimental schistosomiasis: III. Harvest of Schistosoma mansoni cercariae by forced nocturnal emergence from Australorbis glabratus. J. Parasitol. 41, 201e208.

Mardia, K.Y., 1972. Statistics of Directional Data. Academic Press Inc., London, 352 pp.

McCarthy, A.M., 1999. Photoperiodic cercarial emergence patterns of the digeneans Echinoparyphium recurvatum (Echinostomatidae) and Plagiorchis sp. (Plagiorchiidae) from a mixed infection of Lymnaea peregra. J. Helminthol. 73, 59e62.

McIlraith, S.M., 1979. A technique for periodic collection of emerging cercariae from snail hosts. J. Parasitol. 65, 326e327.

Mitchell, J.B., Lees, E.L., Mason, A.R., 1983. Factors affecting the emergence of Gorgoderina vitelliloba cercariae in vivo and in vitro. J. Parasitol. 69, 615e617.

Morgan, J.A., DeJong, R.J., Lwambo, N.J., Mungai, B.N., Mkoji, G.M., Loker, E.S., 2003. First report of a natural hybrid between Schistosoma mansoni and S. rodhaini. J. Parasitol. 89, 416e418.

Mouahid, A., Théron, A., 1986. Schistosoma bovis: patterns of cercarial emergence from snails of the genera Bulinus and Planorbarius. Exp. Parasitol. 62, 389e393.

Mouahid, H., Moné, H., Chaib, A., Théron, A., 1991. Cercarial shedding patterns of Schistosoma bovis and S. haematobium from single and mixed infections of Bulinus truncatus. J. Helminthol. 65, 8e14.

Mouahid, G., Idris, M.A., Verneau, O., Théron, A., Shaban, M.M., Moné, H., 2012. A new chronotype of Schistosoma mansoni: adaptive significance. Trop. Med. Int. Health 17, $727 \mathrm{e} 732$.

Mouchet, F., Théron, A., Brémond, P., Sellin, E., Sellin, B., 1992. Pattern of cercarial emergence of Schistosoma curassoni from Niger comparison with three sympatric species of schistosomes. J. Parasitol. 78, 61e63.

Muhoho, N.D., Katsumata, T., Kimura, E., MigwI, D.K., Mutua, W.R., Kiliku, F.M., Habe, S., Aoki, Y., 1997. Cercarial density in the river of an endemic area of schistosomiasis haematobia in Kenya. Am. J. Trop. Med. Hyg. 57, 162e167.

N'Goran, E., Brémond, P., Sellin, E., Sellin, B., Théron, A., 1997. Intraspecific variability of Schistosoma haematobium in West Africa: chronobiology of cercarial emergence. Acta Trop. 66, 35e45.

Noda, S., Sato, K., Katsumata, T., Nojima, H., Muhoho, N.D., 1986. The influence of shadowing on emergence of Schistosoma haematobium during day time. Jpn. J. Parasitol. 35, 249e251. 
Nojima, H., Sato, A., 1978. The emergence of Schistosome cercariae from the snails. 1. Hourly response of cercarial emergence of Schistosoma mansoni and S. haematobium and effect of light-cut on their emergence. Jpn. J. Parasitol. 27, 197e213.

Nojima, H., Sato, A., 1982. Schistosoma mansoni and Schistosoma haematobium: emergence of Schistosome cercariae from snails with darkness and illumination. Exp. Parasitol. 53, 189e198.

Nojima, H., Sato, A., Matsunaga, K., 1981. The emergence of Schistosome cercariae from the snails. 3. Combined effect of light and temperature on the emergence of Schistosoma mansoni and S. haematobium cercariae. Jpn. J. Parasitol. 30, 405e415.

Norton, A., Rollinson, D., Richards, L., Webster, J., 2008. Simultaneous infection of Schistosoma mansoni and S. rodhaini in Biomphalaria glabrata: impact on chronobiology and cercarial behaviour. Parasite Vectors 1, 43. http://dx.doi.org/10.1186/1756-3305-1-43.

Olivier, L.J., 1966. A continuous flow centrifuge for concentration of Schistosoma cercariae. Am. J. Trop. Med. Hyg. 15, 875e881.

Pages, J.R., Théron, A., 1990a. Analysis and comparison of cercarial emergence rhythms of Schistosoma haematobium, S. intercalatum and S. bovis and their hybrid progeny. Int. J. Parasitol. 20, 193e197.

Pages, J.R., Théron, A., 1990b. Schistosoma intercalatum from Cameroon and Zaïre: chronobiological differentiation of cercarial emergence. J. Parasitol. 76, 743e 745.

Pointier, J.P., Guyard, A., Théron, A., Dumoutier, A., 1984. Le fonctionnement d'un site de transmission a Schistosoma mansoni en Martinique (Antilles françaises). Ann. Parasitol. Hum. Comp. 59, 589e595.

Raymond, K., Probert, A.J., 1991. The daily cercarial emission rhythm of Schistosoma margrebowiei with particular reference to dark period stimuli. J. Helminthol. 65, $159 \mathrm{e} 168$.

Raymond, K., Probert, A.J., 1987. The effect of light and darkness on the production of cercariae of Schistosoma haematobium from Bulinus globosus. J. Helminthol. 61, $291 \mathrm{e} 296$.

Rowan, W.B., 1957. A simple device for determining population density of Schistosoma mansoni cercariae in infected waters. J. Parasitol. 43, 696e697.

Sandt, D.G., 1972. Evaluation of an overlay technique for the recovery of Schistosoma mansoni cercariae. Bull. World Health Organ. 47, 125e127.

Sandt, D.G., 1973. Laboratory comparison of four cercaria recovery techniques. Bull. World Health Organ. 48, 35e 40.

Schutte, C.H.J., 1974. Studies on the South African strain of Schistosoma mansoni. Part 2: the intra-molluscan larval stages. South Afr. J. Sci. 70, 327e346.

Shostak, A.W., Esch, G.W., 1990. Photocycle-dependent emergence by cercariae of Halipegus occidualis from Helisoma anceps, with special reference to cercarial emergence patterns as adaptations for transmission. J. Parasitol. 76, $790 \mathrm{e} 795$.

Standley, C.J., Stothard, J.R., 2012. DNA barcoding of schistosome cercariae reveals a novel sub-lineage within Schistosoma rodhaini from Ngamba Island Chimpanzee Sanctuary, Lake Victoria. J. Parasitol. 98, 1049e1051.

Steinauer, M.L., Hanelt, B., Mwangi, I.N., Maina, G.M., Agola, L.E., Kinuthia, J.M., Mutuku, M.W., Mungai, B.N., Wilson, W.D., Mkoji, G.M., Loker, E.S., 2008. Introgressive hybridization of human and rodent schistosome parasites in western Kenya. Mol. Ecol. 17, 5062e5074.

Su, J., Zhou, F., Lu, D.B., 2013. A circular analysis of chronobiology of Schistosoma japonicum cercarial emergence from hilly areas of Anhui, China. Exp. Parasitol. 2, $421 \mathrm{e} 425$. 
Tanabe, B., 1923. The life history of a new schistosome, Schistosomatium pathlocopticum Tanabe, found in experimentally infected mice. J. Parasitol. 9, 183e198.

Taylor, M.G., 1970. Hybridization experiments on five species of African schistosomes. J. Helminthol. 44, 253e314.

Théron, A., 1975. Chronobiologie des cercaires de Ribeiroia marini (Faust et Hoffman, 1934) parasite de Biomphalaria glabrata: action de la photopériode sur le rythme d'émission. Acta Trop. 32, 309e316.

Théron, A., 1976. Le cycle biologique de Plagiorchis neomidis Brendow, 1970, Digene parasite de Neomys fodiens dans les Pyrennées. Ann. Parasitol. Hum. Comp. 51, $329 \mathrm{e} 340$.

Théron, A., 1979. A differential filtration technique for the measurement of schistosome cercarial densities in standing waters. Bull. World Health Organ. 57, 971e975.

Théron, A., 1980a. Mise en évidence de races chronobiologiques de Schistosoma mansoni a partir des cinétiques d'émissions cercariennes. Cr. Acad. Sci. III-Vie 279e282.

Théron, A., 1980b. Evaluation de la dérive cercarienne dans les sites de transmission des Schistosomoses a partir d'un prélévement journalier unique. Exemple des foyers guadeloupéens a Schistosoma mansoni. Rev. Epidémiol. Santé 28, 131e139.

Théron, A., 1981a. Dynamics of larval populations of Schistosoma mansoni in Biomphalaria glabrata. I- Rhythmic production of cecariae in monomiracidial infections. Ann. Trop. Med. Parasitol. 75, 71e77.

Théron, A., 1981b. Dynamics of larval populations of Schistosoma mansoni in Biomphalaria glabrata. II. Chronobiology of the intramolluscal larval development during the shedding period. Ann. Trop. Med. Parasitol. 75, 547e554.

Théron, A., 1982. Le compartiment cercaire dans le cycle de Schistosoma mansoni, Sambon, 1907. Ecologie de la transmission bilharzienne en Guadeloupe. These Université de Perpignan, 506 pp.

Théron, A., 1984. Early and late shedding patterns of Schistosoma mansoni cercariae: ecological significance in transmission to human and murine hosts. J. Parasitol. 70, $652 \mathrm{e} 655$.

Théron, A., 1985. Le polymorphisme du rythme d'émission des cercaires de Schistosoma mansoni et ses relations avec l'écologie de la transmission du parasite. Vie Milieu 35, $23 \mathrm{e} 31$.

Théron, A., 1986a. Cercariometry and the epidemiology of schistosomiasis. Parasitol. Today 2, 61e63.

Théron, A., 1986b. Chronobiology of schistosome development in the snail host. Parasitol. Today 2, 192e194.

Théron, A., 1989. Hybrids between Schistosoma mansoni and S. rodhaini: characterization by cercarial emergence rhythms. Parasitology 99, $225 \mathrm{e} 228$.

Théron, A., Combes, C., 1983. Analyse génétique du rythme d'émergence des cercaires de Schistosoma mansoni par croisement de souches a pics d'émission précoces ou tardifs. Cr. Acad. Sci. III-Vie 571e574.

Théron, A., Combes, C., 1988. Genetic analysis of cercarial emergence rhythms of Schistosoma mansoni. Behav. Genet. 18, 201e209.

Théron, A., Combes, C., 1995. Asynchrony of infection timing, habitat preference and sympatric speciation of schistosome parasites. Evolution 49, 372e375.

Théron, A., Fournier, A., 1982. Mise en évidence de structures nerveuses dans le sporocyste fils du Trématode Schistosoma mansoni. Cr. Acad. Sci. III-Vie 365e369. 
Théron, A., Moné, H., 1986. Shedding patterns of Schistosoma mansoni and Ribeiroia marini cercariae from a mixed infection of Biomphalaria glabrata. J. Helminthol. 60, $255 \mathrm{e} 259$.

Théron, A., Pointier, J.P., 1995. Ecology, dynamics, genetics and divergence of trematode populations in heterogenous environments: the model of Schistosoma mansoni in the insular focus of Guadeloupe. Res. Rev. Parasitol. 55, 49e64.

Théron, A., Touassem, R., 1989. Schistosoma rodhaini. Intramolluscan larval development:

migration and replication processes of daughter sporocysts. Acta Trop. 46, 39e 45.

Théron, A., Mouahid, A., Moné, H., 1997. Schistosoma mansoni : cercarial shedding patterns from a mixed infection of Biomphalaria glabrata with two (early and late) chronobiological variants. Parasitol. Res. 83, 356e 358.

Théron, A., Pointier, J.P., Combes, C., 1977. Recherches sur les facteurs responsables des densités de cercaires de Schistosoma mansoni en Guadeloupe. Ann. Parasitol. Hum. Comp. 52, 421e433.

Théron, A., Pointier, J.P., Morand, S., Imbert-Establet, D., Borel, G., 1992. Long-term dynamics of natural populations of Schistosoma mansoni among Rattus rattus in patchy environment. Parasitology 104, 291e298.

Valle, C., Pellegrino, J., Alvarenga, N., 1973. Rhythmic emergence of Schistosoma mansoni cercariae from Biomphalaria glabrata: influence of température. Rev. Inst. Med. Trop. Sao Paolo 15, 195e201.

Van Cauter, E., Huyberects, S., 1973. Problems in the statistical analysis of biological time series: the cosinor test and the periodogram. J. Interdiscip. Cycle Res. 4, 41e57.

Williams, C.L., Gilbertson, D.E., 1983a. Effect of alterations in the hearthbeat and locomotor activity of S. mansoni-infected Biomphalaria glabrata on cercarial emergence. J. Parasitol. 69, 677e681.

Williams, C.L., Gilbertson, D.E., 1983b. Altered feeding response as a cause for the altered heart-beat rate and locomotor activity of Schistosoma mansoni-infected Biomphalaria glabrata. J. Parasitol. 69, 671e676.

Williams, C.L., Wessels, W.S., Gilbertson, D.E., 1984. Comparison of the rhythmic emergence of Schistosoma mansoni cercariae from Biomphalaria glabrata in different lighting regimens. J. Parasitol. 70, 450e452.

Yamaguti, S., 1970. On the periodicity of natural emergence of cercariae. In: Singh, K.S., Tandan, B.K. (Eds.), H.D. Srivastava Commem. Vol., pp. 485e492. 